doi: 10.3176/arch.2014.2S.06

\title{
5. DIE SIEDLUNGSPLÄTZE UND GRABUNGEN
}

\subsection{Asva}

Der Fundplatz liegt im Ostteil der Insel Saaremaa, auf dem südlichsten Teil eines Moränenzuges, nahe dem heutigen Dorf Laimjala, in Sichtweite zur Landstraße in Richtung Inselhauptstadt Kuressaare. Im Volksmund trägt die Ortschaft um die im Gelände noch deutlich sichtbaren Reste der vendel- oder vorwikingerzeitlichen Wallanlage den Namen ,Burgbergacker' (linnamäe põld). Mittlerweile wird das Gebiet als Weide- und Grasland genutzt.

Die Küste befindet sich heute in ca. $5 \mathrm{~km}$ Entfernung vom Fundplatz, da sich die Strandlinie im Zuge der Landerhebung der letzten Jahrtausende stetig zurückzog (Abb. 6). Im frühen Limnaea-Stadium der Ostsee ragte der südlichste Zipfel der Moräne, eine inmitten der flachen Insellandschaft seltene geologische Formation, als Halbinsel aus dem Wasser (Jaanits et al. 1982, 136). Nur wenige Kilometer nördlich, auf dem gleichen Moränenzug, befindet sich der zeitgleich besiedelte Fundplatz Ridala.

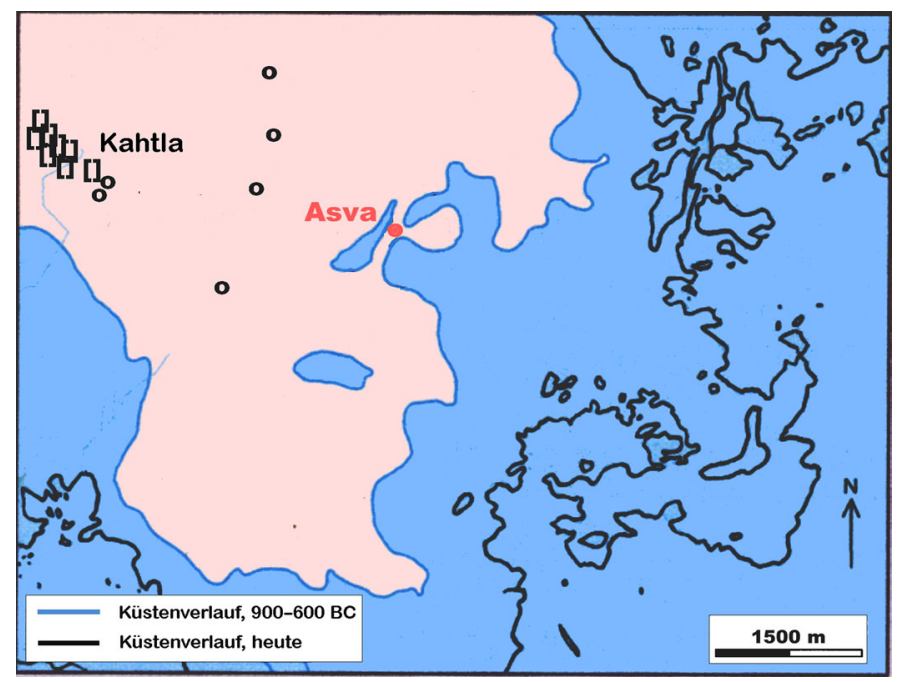

Abb. 6. Reliefkarte mit dem Siedlungsplatz Asva in der von Aivar Kriiska vorgeschlagenen paläogeographischen Rekonstruktion des Uferlinienverlaufs in der Spätbronzezeit (A. Kriiska per E-Mail am 28.01.2014), und den archäologisch erfassten, vorgeschichtlichen Bodendenkmälern. [] - Steinkistenund tarandgräber; o - Schalensteine, mit Datierung in die Vorrömische Eisenzeit und jünger; Lôugas \& Selirand 1989, 205 f.). Quelle: http://xgis.maaamet.ee/xGIS/XGis 
Den Kalkulationen Richard Indrekos zufolge kam dieser Moränenzug erst im Spätstadium der Littorina-See als Halbinsel an die Wasseroberfläche. Mit den frühesten Besiedlungsspuren ist demnach erst zum Ende der Steinzeit zu rechnen (Indreko 1939b, 19 f.; 1961, 417). Älteste Scherbenfunde mit Schnur- und Kammverzierung, die vereinzelt und sekundär verlagert zwischen dem bronzezeitlichen Fundmaterial von Asva auftauchen, lassen sich grob in das frühe zweite vorchristliche Jahrtausend datieren (Jaanits et al. 1982, 136; Lang \& Kriiska 2001, 93 f.). Der Siedlungsplatz liegt heute etwa acht Meter über dem Meeresspiegel, der Höhenunterschied beträgt bei dem sich leicht neigenden Gelände einige Meter. Aus dem kürzlich von Aivar Kriiska rekonstruierten ungefähren Küstenverlauf der Spätbronzezeit, berechnet und prognostiziert aus der Verbreitung der neolithischen Ufersiedlungen, der Geschwindigkeit der Landerhebung und dem Neigungsgradienten, befand er sich auf einem schmalen Landarm zwischen Meer und einem lagunenartigen Gewässer (Abb. 6; zur Methodik: Jussila \& Kriiska 2004; Kriiska \& Selart 2005). Von einer Fläche von $3500 \mathrm{~m}^{2}$, der Platz misst ca. $90 \mathrm{~m}$ in der Länge und $47 \mathrm{~m}$ an der breitesten Stelle, wurden nur ca. ein Fünftel archäologisch untersucht.

Von den Hinterlassenschaften der sog. Burgbergschicht (hier: Asva III) ist nur vergleichsweise wenig bekannt, sie kann nur kurz und bündig charakterisiert werden (dazu Lõugas 1967; Sperling 2006, 15 f.). Bemerkenswert ist, dass es eine gegenüber Asva synchrone Bebauungsphase (u. a. mit Wallkonstruktion) in der Siedlung von Iru und im finnischen Lieto gibt (Luoto 1984; Lang 1987a; 1987b).

In dieser Phase, in der Mittleren Eisenzeit nach estnischer Periodisierung (2. Hälfte des 1. Jahrtausends u. Z.), wurde der noch heute im Gelände sichtbare Burgwall von Asva errichtet. In den durch die West- und Südostwälle gegrabenen Profilen wird die Siedlungs- und Bauabfolge gut sichtbar (Indreko 1939b, 21 f., Taf. II; Lõugas 1967, 84 f., 92). Dabei wird das spätbronzezeitliche Schichtenpaket (hier: Asva I und II) von einer sterilen, aus reinem Strandkies bestehenden, Aufschüttung abgelöst, die zum mutmaßlichen Zweck der Begradigung des Geländes im Zuge der Wallerrichtung und Innenbesiedlung entstand. Die Funde der Schicht des sog. Burgbergs (Asva III) treten, insofern die rezenten Pflugstörungen oder sonstige Eingriffe in den Boden den ursprünglichen Schichtenaufbau nicht störten, erst oberhalb der Strandkiesdecke auf (siehe auch Tab. 2, Abb. 12; Taf. 65).

Neben den Resten mutmaßlicher Wallkonstruktionen sind der Phase Asva III keine der archäologischen Befunde eindeutig Wohnbauten zuzuordnen. Einzig in Asva A und F sind einige Steinpflasterungen aus Schieferplatten als mutmaßliche Fußböden bzw. deren Reste anzusprechen (Indreko 1939b, 21 f., Taf. II; Lõugas 1966a, 16, Plan 6a-b). Die Fundmengen der mitteleisenzeitlichen Periode sind insgesamt vergleichsweise klein, und das betrifft auch das Spektrum der Objekte. Der Fundreichtum ist erst mit den Grabungen in tiefer gelegenen, spätbronze- und früheisenzeitlichen Schichtzusammenhängen eingetreten. ${ }^{27}$

\footnotetext{
27 Lõugas dazu (1967, 92): (es) kann zur Charakterisierung des obersten Fundkomplexes noch gesagt werden, dass Bernstein, Gussformenfragmente, knöcherne Schmucknadeln u. a. Funde, die für die untere (spätbronzezeitliche) Schicht charakteristisch sind, dort nicht mehr vorkommen.
} 
Tabelle 2. Darstellung der Abfolge der einzelnen Siedlungsschichten von Asva

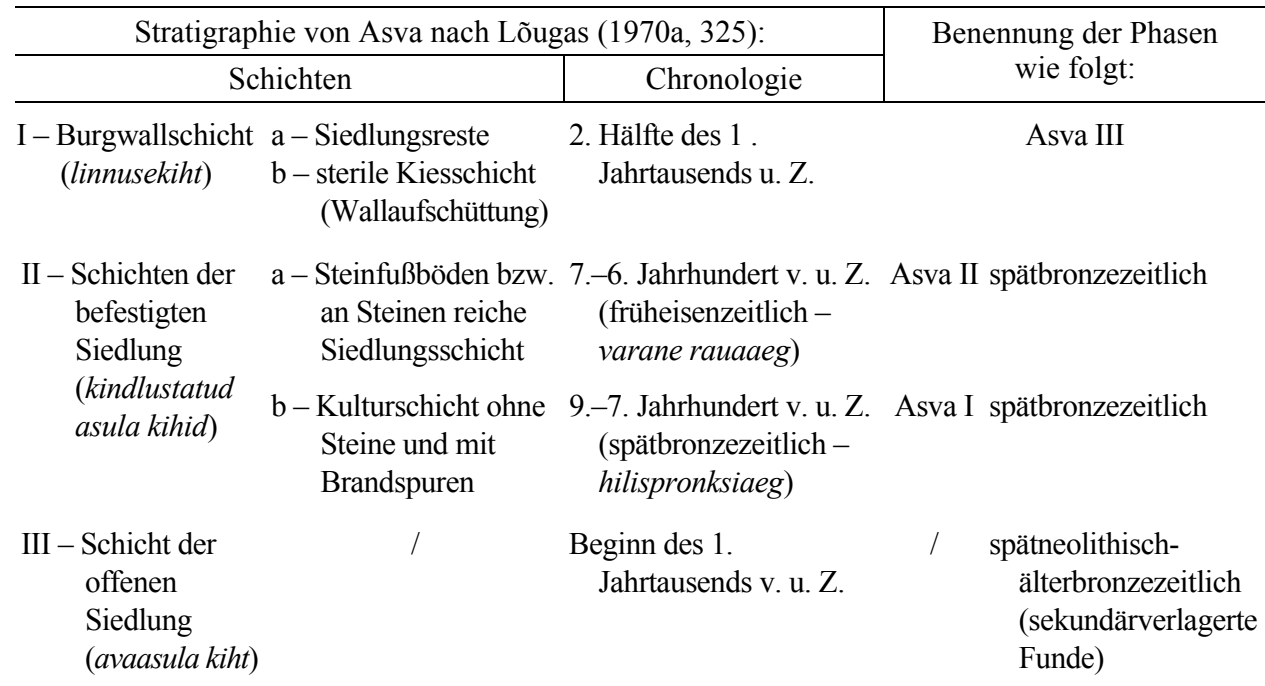

An Keramik fallen hauptsächlich feinkeramische Schalen auf. In der Oberflächenbehandlung und scharfkantigen Profilierung sind diese in punkto Gestalt und Qualität der bronzezeitlichen Keramik ähnlich. Sie sind auch nur dann wirklich gut unterscheidbar, wenn verzierte Rand- oder Schulterpartien erhalten sind. Die mitteleisenzeitliche Ware ist ausgesprochen dünnwandig und fein gemagert, betont ist stets der Schulterabsatz mittels eines scharfen Wandknicks oder einer zusätzlich herausmodellierten Rippe (Taf. 65: 1). Typisch für diese Periode scheinen die am Umbruch und/oder am Rand befindlichen Horizontallinien, auch in Begleitung von Fischgräten- oder Sparrenmustern, zu sein (Taf. 65: 3-4; Lõugas 1967, 86 ff., Abb. 5: 1-6; Lõugas \& Mägi-Lõugas 1994, 29 f., Abb. 2, Taf. VII). Töpfe (u. a. solche mit Randknick) treten im keramischen Fundmaterial von Asva III seltener in Erscheinung (Lõugas 1967, 86, Abb. 5: 7; Sperling 2006, Taf. I: 5).

Unter den Asva-Funden sind auch einige jüngereisenzeitlicher Datierung (z. B. Eisenpfeilspitzen und einige Bronzeobjekte), sie lassen sich jedoch stratigraphisch nicht klar zuordnen. Nach Ausweis dieser Funde ist der sog. Burgberg von Asva auch in jüngeren Perioden sporadisch aufgesucht worden (Vassar 1955, 129; Lõugas 1967, 82; Sperling 2006, 15 f., Taf. I).

\subsubsection{Die Grabungen im West- und Südteil-Asva A-D (R. Indreko)}

Nach ersten Prospektionen (1931) wurde 1934 eine erste Kampagne im Nordwestbereich der Siedlung unter Leitung von Richard Indreko unternommen. Dabei wurde ein $\mathrm{W}-\mathrm{O}$ ausgerichtetes Areal von $54 \mathrm{~m}^{2}$ freigelegt. Dort wurden 325 Fundnummern verteilt. Im Jahre 1938 folgte dann ein weiterer Anschnitt am Westrand des Burgberg-Plateaus, die Sonda A $\left(99 \mathrm{~m}^{2}\right)$, die im Jahre 1939 am Abhang und Fuße sowie nach Norden (C) um ca. $45 \mathrm{~m}^{2}$ erweitert wurde (Abb. 7). 

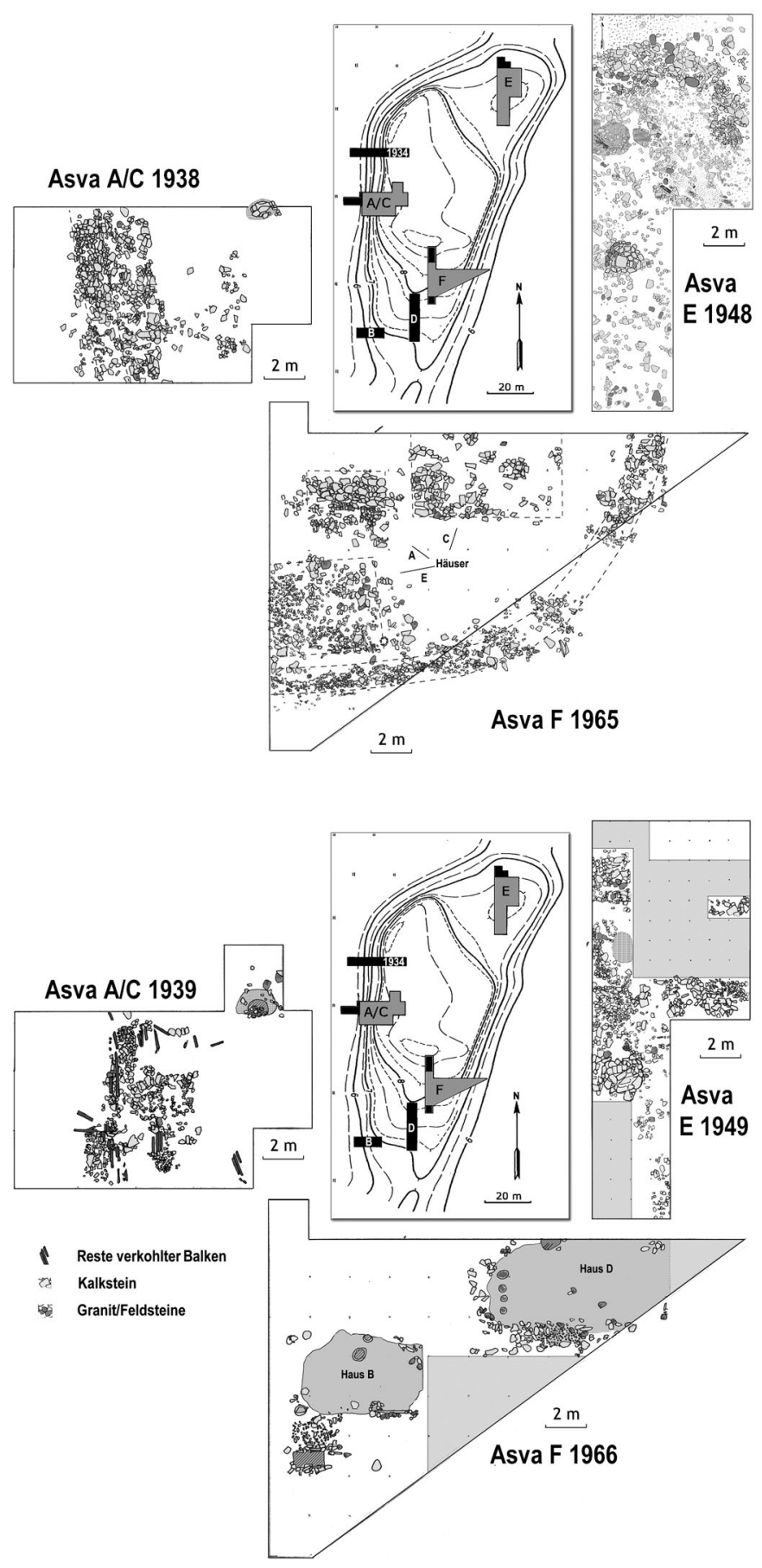

Abb. 7. Die jüngeren und älteren Siedlungsphasen Asva II (oben) und Asva I (unten) in den verschiedenen Grabungsdokumentationen (nach Indreko 1939b; Schmiedehelm 1949; Vassar 1955; Sperling 2006; modifiziert). 
Hinzu kamen neue Schnitte im Süden der Fläche (B, D), die den Verlauf des Südwalls erfassen sollte. Insgesamt wurde von Indreko in den Jahren 1934, 1938 und 1939 eine Fläche von $235 \mathrm{~m}^{2}$ untersucht (mit insgesamt 1700 Fundnummern).

In allen Grabungsteilen wurden mehrere Siedlungsschichten erfasst. Im westlichen Wallbereich wurde unter den ersten $20 \mathrm{~cm}$, i. d. R. stark pfluggestört, eine bis zu $50 \mathrm{~cm}$ starke, ruß- und holzkohlehaltige Kulturschicht angetroffen. Diese enthielt Reste einer abgebrannten Wallkonstruktion und Teile einer Steinpflasterung aus Schieferplatten. Sie wird dem Siedlungshorizont des Burgbergs zugeschrieben (Indreko 1938, 1; 1939a; 1939b, 22, Taf. II). Von den tieferen Kulturschichten wird diese durch eine, sterile' bzw. fundleere, im Wallbereich 30-60 cm starke, Strandkiesschicht getrennt. Sie wird als eine künstliche Terrainbegradigung des Befestigungsabschnitts zu Zeiten der eisenzeitlichen Wallerrichtung interpretiert (Indreko 1938, 3, Abb. 2; 1939b, 5, 22, Taf. II). Unter dieser Zwischenschicht konnte im Bereich Asva A/C mindestens eine weitere Kulturschicht mit vielen Keramik- und Knochenfunden beobachtet werden. Sie wird als dunkel und rußig beschrieben, enthält ebenfalls Reste von Pflasterungen mit Kalksteinplatten und verkohlten Balkenresten (Indreko 1934, 1 f., Abb. 1b-c, 2). Ganz offensichtlich handelt es sich dabei um das bronzezeitliche Schichtenpaket mit einem zwischenliegenden Brandhorizont, das von den Ausgräbern in den anderen Grabungsteilen von Asva angetroffen wurde.

In diesem Schichtenpaket wird eine untere Schicht nur knapp als stärker und kompakter als die obige geschildert (Indreko 1938, 3; 1939a, 5; 1939b, 22). Schwierig bleibt die stratigraphische Trennung und Zuordnung der Baustrukturen, speziell der Balkenreste. Einige verkohlte Hölzer werden im westlichen Randbereich der Sonda zusammen mit den mutmaßlichen Resten einer Trockenmauer aus Kalksteinplatten festgehalten. Indreko vermutet darin Spuren einer älteren Besiedlungsphase (Haus oder Zaun), die offenkundig zerstört und an der gleichen Stelle durch eine Mauerung ersetzt bzw. ergänzt wurde (Indreko 1939b, 22). $\mathrm{Ob}$ die Balkenreste tatsächlich der Siedlungsbegrenzung (Befestigung?) oder einem Wohnbau angehörten, lässt sich dem Befund nicht eindeutig entnehmen. Indreko sieht diese als Vorgänger oder Ergänzungsbau zur Trockenmauer. Bemerkenswert ist, dass in den anderen Grabungsteilen Asva E und F keinerlei Balkenreste dokumentiert bzw. überliefert sind, was sich möglicherweise durch eine unterschiedliche Bodenerhaltung erklärt. Bauhölzer wurden zweifelsohne für die Hausbauten verwendet, was sich im Befund in den Grundrissen und teilweise sichtbaren Pfostenlöchern (Asva F) zu erkennen gibt. Für die Errichtung von Balkenzäunen für die Umgrenzung der gesamten Siedlung fehlt es indes an Belegen. Wie in Asva A/C lassen sich in den übrigen Grabungsteilen Reste von Trockenmauerungen aus örtlich anfallenden Schieferplatten erkennen, allerdings erst in der steinreichen Phase Asva II (Abb. 7).

Mit zunehmender Tiefe nehmen die Gussformen zu, die sich verstärkt um die in der 1939er Grabung freigelegte Herdstelle (auch Gießerplatz) gruppieren. Wie im Grabungsteil Asva F auch, scheint hier die Metallverarbeitung zurzeit der ältesten Phase (hier benannt: Asva I) stattgefunden zu haben. Genauere 
Beobachtungen zur Verteilung der Funde (Keramik etc.) auf die jeweiligen Siedlungsphasen blieben jedoch aus. Anhand der Stilmerkmale der Keramik und Gussformen datierte Indreko (1939b, 35 f.) die unteren Schichten in die jüngere Bronzezeit, was seiner Auffassung nach dem 8. und 7. Jahrhundert v. u. Z. entspräche. $\mathrm{Zu}$ einem späteren Zeitpunkt sprach Indreko $(1961,417)$ von unteren, mittleren (beide spätbronzezeitlich) und oberen (älter- oder mitteleisenzeitlich) Schichten. Indreko vermochte eine grobe, dickwandige von einer dünnwandigen Keramik feiner, profilierter Machart zu unterscheiden, legte sich aber vorzeitig darauf fest, dass letztere, weil qualitätsvolle (u. a. mit Politur) auf die oberen Schichten verteilt gewesen sei. ${ }^{28}$ Er erkannte zwar einige Gefäßscherben der Henkelkeramik, in Stil und Technik an polnische Gruppen des Hallstatt-Kulturkreises erinnernd, als spätbronze- bzw. früheisenzeitlich an. Er vermutete aber in der großen Masse an Knickwandschalen eine jüngere Periodenzugehörigkeit (Indreko 1939b, 35 f.).

Die Schnitte B und D im Südwest- und Südteil stellen Sondagen zur Klärung des Verlaufs von Wall- und Mauerkonstruktionen dar. Besondere Befunde haben sich dort nicht ergeben, dort wurden nur wenige Fundnummern verteilt. An einigen Stellen beträgt die Stärke der Kulturschicht 50-60 cm, z. T. sind auch Brandspuren und Steinmaterial nachweisbar. Mauer- oder Zaunstrukturen wurden dort keine erfasst.

Im Wallbereich von Asva A wurde Indreko zufolge unter den als bronzezeitlich angesprochenen Schichten noch eine weitere Kulturschicht, nur wenige Zentimeter dünn, ausgemacht. Sie soll unter dem Walllabschnitt nach Westen weitergelaufen sein und einige Knochen und etwas Keramik beinhaltet haben. Zu Art und Zahl der Funde aus dieser Schicht ist jedoch nichts zu erfahren, im Bericht werden auch keine Fundnummern erwähnt (Indreko 1939a, 10, Abb. 2 und 17).

\subsubsection{Die Grabungen im Nordteil - Asva E (A. Vassar und M. Schmiedehelm)}

Im Nordteil der Siedlung wurde in zwei Sommerkampagnen eine Fläche von $129 \mathrm{~m}^{2}$ untersucht. Die Fundausbeute ist reichlich, es wurden über 2000 Fundnummern vergeben (mit über 6600 Gefäßscherben). Auch im Nordteil gibt es Spuren von Metallgussaktivität mit einer hohen Zahl an Gussformen. In Asva E fehlt es an Funden der eisenzeitlichen Burgwallsiedlung, auch an Hinweisen auf eine Stein- oder Holzwallkonstruktion (wie in Asva A). Man mutmaßte, dass der Nordsporn nach der Spätbronzezeit entweder nicht mehr besiedelt wurde oder die jüngeren Siedlungsreste weggepflügt wurden (Vassar 1955, 116; Lõugas 1967, 84; 1970a, 328 f.).

In den Berichten der Ausgräber ist von mehreren Bauphasen die Rede, die alle der Spätbronze- und Früheisenzeit angehören (Vassar 1948, 15 f., 22 f.; Vassar 1955, 116). Zunächst ist man auf einen mit Kalksteinen gepflasterten Horizont,

${ }^{28}$ Indreko 1939a, 10; 1939b, 35 f.: Die Erkenntnis, dass die Feinkeramik der bronzezeitlichen Asva-Gruppe in qualitativen und ästhetischen Gesichtspunkten der Keramik der Mittleren Eisenzeit Estlands kaum nachsteht, reifte erst mit Anwachsen der Fundmengen in den nächsten Siedlungsgrabungen. 
stellenweise mit einer bis zu $40 \mathrm{~cm}$ starken Kulturschicht mit Brandspuren (Holzkohle- und Aschereste) gestoßen, gefolgt von einer ca. $5 \mathrm{~cm}$ fassenden hellsandigen ,Zwischenschicht'. Darunter kam eine weitere Schicht zutage, von ähnlich dunkler Farbe und Konsistenz, aber intensiver und mächtiger als die obere (Vassar 1948, 13 ff., 23). Trotz der Einsicht in die Schichtenfolge wurde nicht nach Schichten gegraben. Bereits zu Beginn der Grabungen gab sich am nördlichen und östlichen Rand des freigelegten Areals eine aus Kalksteinplatten bzw. dessen Resten dicht gepackte, ursprünglich womöglich geschichtete Einfriedung zu erkennen, die jedoch als solche stehen gelassen wurde (Abb. 7). In der Folge hat man um die Trockenmauer herum gegraben, ohne Schnitt oder Profile in diesem interessanten Grenzbereich anzulegen. Erhalten blieb eine ungefähr halbmeterhohe Einfriedung, von der angenommen wird, dass sie in der älteren und jüngeren Bronzezeitsiedlung bestand. Vassar vermutete eine nur kurzzeitige Unterbrechung der Siedlungstätigkeit, wahrscheinlich infolge eines Brandes, was eine Fundtrennung oder deren Zuordnung nach Schichten nicht möglich mache. Beobachtet wurde lediglich, dass in der älteren Schicht die Menge der Tierknochen deutlich zunahm (Vassar 1948, 6 f., 22; 1955, 116 ff.). Ein Hausgrund lässt sich aus den Steinlegungen nicht erschließen. Interessant ist eine kreisförmige Steinplattenstruktur, die vom Ausgräber mit der Metall- und Keramikverarbeitung in Verbindung gebracht wird.

\subsubsection{Die Grabungen im Südostteil - Asva F (V. Lõugas)}

Die letzte, zweijährige Grabungskampagne in Asva (1965-1966) fand an der Südostseite der Siedlung statt. Vello Lõugas hatte sich zum Ziel gemacht, Verlauf und Bebauung der Siedlungsgrenze zu klären und endlich Klarheit in die stratigraphischen Zusammenhänge zu bringen (Lõugas 1970a, 324). Es gelang ihm letztendlich auch, über die Befunddokumentation zu verlässlichen Datierungsunterlagen zu kommen.

Im Südostteil Asva $\mathrm{F}$ wurde die größte zusammenhängende Fläche dieser Siedlung untersucht $\left(206 \mathrm{~m}^{2}\right)$. Aus diesem Bereich stammen auch die für die Chronologieproblematik relevantesten Funde. Besonders die Keramik ist in Asva F reichlich vertreten (ca. 14.000 Gefäßscherben), darunter viel an Henkel- und Knickwandkeramik. Insgesamt wurden 1941 Fundnummern vergeben. Ein offizieller Grabungsbericht der 1965er-Kampagne ist im Tallinner Archiv nicht mehr auffindbar, erhalten sind indes die Pläne und Profilzeichnungen. Es lässt sich also nur auf den schriftlichen Bericht von 1966 (und zugehörige zeichnerische Dokumentationen) zurückgreifen. Lõugas liefert auch in seiner Dissertation (1970a) eine eingehende Zusammenfassung aller seiner Grabungsergebnisse.

Letztlich gehen Lõugas‘ Beobachtungen zur Siedlungsabfolge im Südostteil Asvas mit denen von Indreko, Vassar und Schmiedehelm in den übrigen Grabungsteilen konform. Seine Untersuchungen haben eine Aufeinanderfolge zweier spätbronzezeitlicher Wohnphasen aufzeigen können, die erst während der 
Mittleren Eisenzeit von einer Neubesiedlung mit Wallaufschüttung überlagert werden (Lõugas 1966a, 10; 1967, 86 ff.). Sporadische Einzelfunde sind noch jüngeren Alters, aber nicht direkt mit Befunden in Verbindung zu bringen.

Wie in früheren Grabungen dokumentiert, wird die sog. Burgbergschicht durch eine kompakte Sterilschicht aus Strandkies vom zweifachen Besiedlungshorizont der Spätbronzezeit getrennt. Eine Brandschicht steht zwischen zwei Phasen mit jeweils zwei bzw. drei Wohnbauten, die sich zudem in Ausrichtung und Bauart (Stampf- und Steinfußböden) voneinander unterscheiden (Lõugas 1966a, 27 ff.; 1970a, 334 ff.). Auf diese beiden bronzezeitlichen Siedlungsphasen verteilt sich reichlich Fundmaterial (u. a. Metallguss). Erst die Grabungen in Asva F haben eine ausreichende Informations- und Arbeitsgrundlage für Untersuchungen zu Siedlung und Handwerk der Bronzezeit in Estland geschaffen.

\subsubsection{Siedlungsabfolge-Asva $F$}

Die Stratigraphie der Siedlung, insbesondere deren Hiatus, markiert durch einen Brandhorizont, und deren Neubebauung innerhalb einer keramischen Stilperiode hat Lõugas mit seinen Grabungen in der Sonda F dargestellt und beschrieben (1970a). Die dort festgehaltenen Beobachtungen bildeten für Sperling (2006) die Grundlage für den Versuch, die verschiedenen Fundgruppen (Gefäßkeramik, Gießerfunde, Knochen- und Geweihgeräte u. a.) ihren stratigraphischen Kontexten nach zuzuordnen und zu untersuchen. An dieser Stelle soll ein Überblick über die stratigraphischen Zusammenhänge der Siedlung präsentiert werden.

Lõugas (1970a, 331 f.) verweist auf die zwei Belegungsphasen der Spätbronzezeit, die auch in den Grabungsteilen Asva A und E beobachtet wurden. Demnach scheint es in allen untersuchten Siedlungsteilen im Zuge der Unterbrechung und Neubesiedlung keine gravierenden Umbauten gegeben zu haben. Zwar zeichnen sich die Wohnbauten im archäologischen Befund der Grabungsareale im Westund Nordteil nicht klar als solche ab, allerdings konnte dort nachgewiesen werden, dass Feuerstellen über beide Siedlungsphasen hinweg weitergenutzt wurden. Nur Form und Größe der Herdplätze wurden leicht verändert, etwa durch Steinkonstruktionen ergänzt.

Überall steht der Siedlungsabbruch (Asva I) mit einem Brandhorizont in Verbindung, welcher an einigen Stellen wiederum durch sog. Zwischenschichten aus Lehm oder Kies überlagert wird. Allerdings, so stellt Lõugas fest (ebd.), kann die Pause zwischen den beiden Phasen keine allzu lange gewesen sein. In dem von ihm untersuchten Grabungsteil Asva F wurden abermals zwei spätbronzezeitliche Bauphasen beobachtet, wieder wurde die Siedlungsunterbrechung durch eine Brandschicht und künstliche Erd- und Lehmaufschüttungen markiert. Die Befunde waren dort allerdings besser als in den übrigen Grabungsteilen erhalten und strukturiert. Vielversprechend für die Dokumentation sind die Wandverläufe, Pfostenspuren und Steinpflasterungen (der Fußböden). Erstmals wurden in Asva die Konturen und Ausrichtungen verschiedener Hausbauten sichtbar. 
Asva ist der einzige Fundplatz unter den estnischen Bronzezeitsiedlungen mit einer im Großen und Ganzen gut nachvollziehbaren Siedlungsabfolge (inkl. Abbruch und Neubau), wenn auch viele Unklarheiten in Bezug auf einige Befunde, etwa Art und Struktur der Begrenzung bzw. Einfriedung, geblieben sind. Maßnahmen künstlicher Befestigung werden Lõugas“ eigenen Erkenntnissen erst in Zeiten der mitteleisenzeitlichen Burgwallerrichtung sichtbar. Worauf indes die angesichts der Befundsituation ungerechtfertigte Kategorisierung der Siedlungsphasen Asva I und II als ,befestigt' gründet, dies wird an keiner Stelle so recht deutlich. Die Idee und Überzeugung bezüglich der Verteidigungsdisposition erwächst vielmehr aus dem Denken, auch aus der zeitgeistlichen Strömung der Forschung, dass Asva in ihrem mutmaßlichen Status einer bronzezeitlichen Mittelpunktsiedlung zwangsläufig ein Wehrcharakter zugekommen sein müsse. Die moderate Dimension der künstlichen Begrenzungsmaßnahmen, die Bronzezeitsiedlung war lediglich durch eine leichte Trockenmauer umfriedet, entspricht jedoch nicht dem Bild einer sog. befestigten Siedlung - auch nicht im Sinne symbolischer Machtdemonstration. Desweiteren entbehrt die periodische Trennung in Spätbronzezeit (nach Lõugas Asva I) und Früheisenzeit (Asva II) jeglicher Beweisgrundlage, doch auch dazu an späterer Stelle mehr (Kap. 9).

Das was die Untersuchungen am Grabungsteil Asva F so interessant und hilfreich für Einblicke in die bronzezeitliche Siedlungssituation macht, ist die dokumentierte Abfolge zweier auf den ersten Blick unterschiedlicher Wohnphasen. Die dichte Schichtenabfolge und das reichhaltige Keramikmaterial bezeugen Entwicklungen, die in einem kurzen Zeitraum stattgefunden haben müssen, denn das keramische Fundgut bewegt sich im gleichen Stilhorizont. Zu den nennenswerten Neuerungen der Siedlungsgeneration nach einer mutmaßlichen Brandkatastrophe gehört die erstmalige Verwendung des örtlichen Kalksteins als Baumaterial und die Einstellung der vormals intensiv betriebenen Metallverarbeitung (Bronzeguss). Ansonsten sind Wohn- und Wirtschaftsweise von keinerlei gravierenden Umgestaltungen betroffen, ein echter Bruch im bronzezeitlichen Siedlungswesen tritt erst mit der Aufgabe der Siedlung Asva II ein.

Kurz sei auch die von Lõugas (1970a, 325) erwähnte Schicht der offenen, ,unbefestigten' Erstbesiedlung von Asva angesprochen, deren Spuren und Reste jedoch nur im Westteil von Asva (1934; A/C) in Form einer wenige Zentimeter dünnen Kulturschicht zum Vorschein kamen. Im dortigen Grabungsprofil ist zu sehen, wie diese unter der bronzezeitlichen Siedlungsgrenze ausläuft. Datierende Funde aus dieser Schicht wurden keine dokumentiert, auch wenn Gefäßscherben und Knochenfunde erwähnt werden (siehe oben). Unter den Siedlungsfunden von Asva (alle Grabungsteile) sind vereinzelte Gefäßscherben ,epineolithischer" Machart (u. a. schnurverziert), vermutlich sekundär verlagerte und einer Vorgängerbesiedlung an diesem Platz zugehörig. Lõugas' zeitliche Einordnung seiner sog. Phase III (Beginn 1. Jahrtausend v. u. Z.; 1970a, 325) hängt offensichtlich mit einigen Knochenartefakten aus Schichtenzusammenhängen von Asva I und II zusammen. Dazu gehören sog. Doppelknöpfe und Nadeln, die in ihren Formen nach an Nordische Metallobjekte der Montelius-Periode IV erinnern und, so Lõugas, diesen 
nachempfunden seien. Da sich die übrigen, stratigraphisch fixierten Fundgruppen von Asva I (v. a. Keramik, Gießerfunde) mit dieser Frühdatierung nicht recht vereinen lassen, wurde Lõugas offensichtlich genötigt, die Lebensdauer der Siedlung etwas zu ,strecken'. Die schnurverzierten Keramikscherben indes finden keine plausible Berücksichtigung in Verbindung mit der bezüglich ihres Alters fraglichen Vorgängerphase. Auf die Problematik der chronologischen Einordnung der Knochengeräte wird an anderer Stelle näher eingegangen (Kap. 9). Im Folgenden soll die Siedlungsstratigraphie von Asva an den Ergebnissen der Lõugasschen Grabungskampagne erläutert werden (Abb. 8).

\subsubsection{Asva F: Häuserhorizont A/C/E (Asva II)}

Der Großteil der über die Kalksteinplatten sichtbaren Hausstrukturen wurde während der 1965er Grabungskampagne freigelegt. Leider fehlt der schriftliche Bericht zu den dort stattgefundenen Arbeiten, so dass in der Bewertung und Deutung der Befunde nur die zeichnerischen Dokumentationen (Zeichnungen der Plana und Profile) und der Bericht der Kampagne des Folgejahres (1966) befragt werden können (Lõugas 1965, Plan 12-13; auch Lõugas 1970a, mit Plänen).

Lõugas berichtet, dass bereits zu Beginn der Arbeiten in Asva F, nach Abtrag des oberen pfluggestörten Horizonts (Burgwallphase), den Resten der Wallaufschüttung und der sterilen Kiesschicht, bereits ab 35-40 cm Tiefe (von Feldkante) kleinere und größere Steinplatten, sorgfältig gelegt und viele in situ, zum Vorschein kamen.

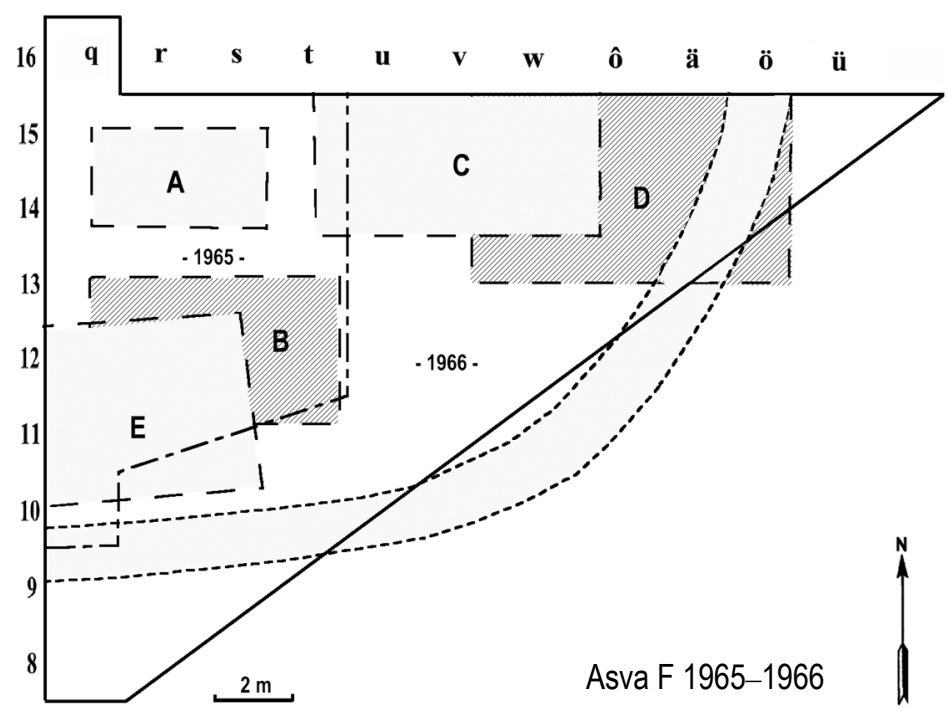

Abb. 8. Grabungsteil Asva F. Entwurf der Hausbauphasen B/D und A/C/E (Asva I und II) mit rekonstruiertem Verlauf der Einfriedung (nach Lõugas 1970a; Sperling 2006). 
Der Form und Ausdehnung der regelrecht gepflasterten Schieferplatten nach zu urteilen, handelte es sich um die Reste von Fußböden mindestens zweier WestOst ausgerichteter Wohnbauten. Die reichlich auftretende Keramik, darunter solche von grober, dickwandiger Machart mit Grübchenmuster, Besenstrich und Textilabdrücken an der Oberfläche sowie einigen Knickwand- und Hängegefäßen mit Griffknubben, entsprach dem spätbronzezeitlichen keramischen Fundspektrum aus den anderen Grabungsteilen von Asva (Lõugas 1970a, 333 f.).

Über die freigelegten Steinplatten konnten einige Wandverläufe erschlossen werden, zu mindestens zwei rechteckigen Hausböden gehörig. Im Nordwestteil (13-14/q-s) waren ca. dreißig, annähernd rechteckförmige Kalksteinplatten, die meisten mit Maßen von 40-60 cm mal 20-30 cm, längs west-östlich ausgerichtet und ergaben eine Struktur von ca. $4 \mathrm{~m}$ in der Länge und $2 \mathrm{~m}$ in der Breite. Lõugas bezeichnete diesen Befund als ,Hausgrund A'. In der 1966er Kampagne wurde die Grabungsfläche nach Osten hin erweitert und in ca. zwei Metern Abstand eine weitere Pflasterung erschlossen, die mit ,C' bezeichnet wurde. Die Steinbodenlege von A schien in einigen Teilen gestört gewesen zu sein, erhalten war aber in ihrer Südostflanke (13-14/s) eine annähernd quadratische Steinpackung, die vom Ausgräber als Reste einer Türschwelle gedeutet wurde (Lõugas 1970a, 332, Taf. 93; Jaanits et al. 1982, 172, Abb. 110). In der Grundstruktur ergäbe sich für den Befund A ein rechtwinkliger Längsbau von ca. $16 \mathrm{~m}^{2}$ Fläche, also mit ausgesprochen kleinen Ausmaßen. Lõugas hielt es für möglich, dass die Reste der Steinböden A und C ursprünglich ein und demselben Wohnbau angehörten, zumal deren südliche Wandverläufe in einer Flucht liegen. Die ca. 1,5 m breite Lücke zwischen den Steinplatten könne auf eine spätere Störung zurückgehen und der Befund A/C ein Langhaus ergeben. Zu den Ausmaßen, der Art und Konstruktion dieses ca. $12 \mathrm{~m}$ in der Länge messenden Baus wird sich aber nicht weiter geäußert. Wegen der fehlenden Pfostenfärbungen im Befund kann über die ursprüngliche Ausrichtung und Konstruktion des Hauses nur gemutmaßt werden. Dennoch spricht trotz der geringen Fläche des mit A bezeichneten Hausgrunds nichts gegen eine Deutung als Einzelbau. Zumindest lassen sich in der räumlichen Verteilung der Keramik unterschiedliche Gebrauchs- und Aktivitätszonen ablesen, hinter denen sich eventuell getrennte Haus- bzw. Wohnbereiche verbergen (siehe Kap. 8.1.1; Sperling 2006, 95 f., Abb. 27).

Im Südteil von Asva F kam ab einer Tiefe von 70-80 cm reichlich Steinmaterial zum Vorschein (Abb. 9). Auf einer Fläche von ca. sechs mal sechs Metern befinden sich viel Steinbruch und, darunter sind auch einige größere Kalksteinplatten wie in den Befunden $\mathrm{A}$ und $\mathrm{C}$, einige vermutlich gestört oder verlagert. Es ist wegen der Kompaktheit und Dichte der Steine in diesem Bereich anzunehmen, dass sich auch dort ein Haus befand. Zumindest ergibt sich aus der Verteilung einiger Feldsteine und einiger senkrecht im Boden stehender Schieferplatten mutmaßliche Wandkonturen. Auch Lõugas (1970a, 333) vermutete hierin die Reste eines mit Steinen ausgelegten, rechteckigen Hausbodens. An dieser Stelle, unter der Steindecke des Hauses E (Abb. 10), kamen die gut erhaltenen Reste eines Vorgängerhauses zutage, begleitet von reichlich Keramik und Gussformen (sog. Gießerhaus B). 


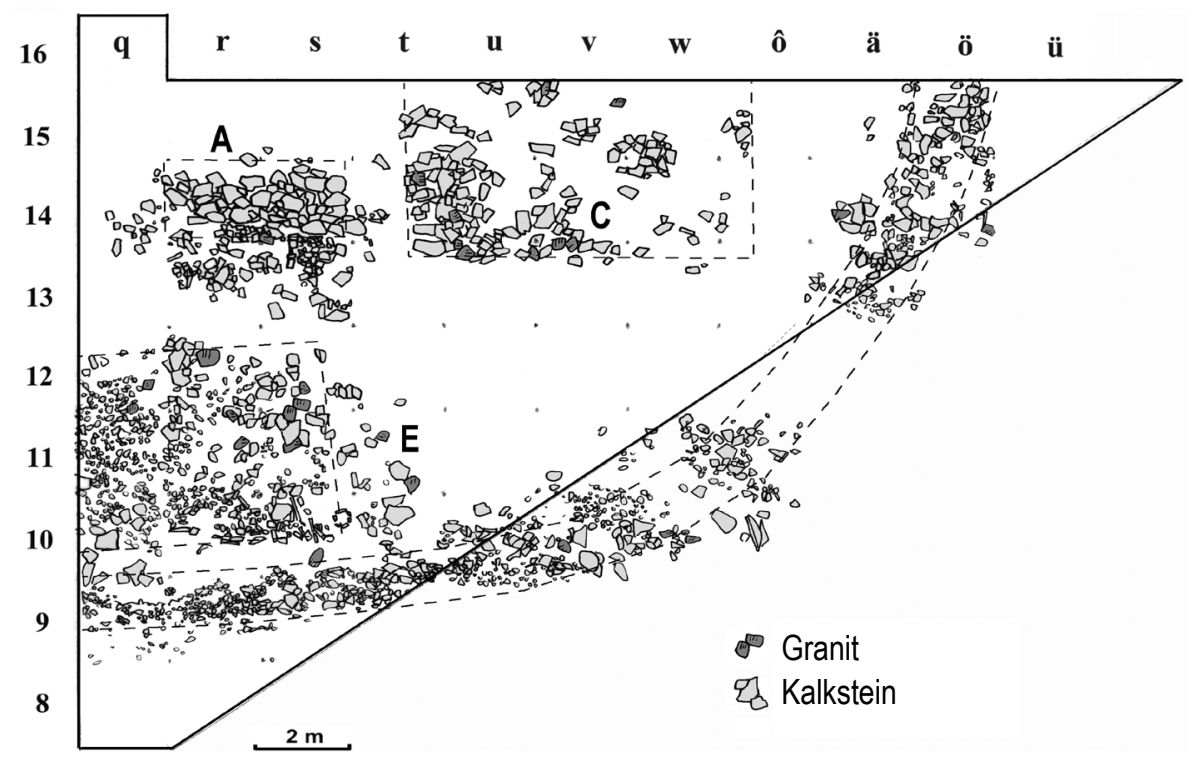

Abb. 9. Die Häuserphase A/C/E (Asva II) im Grabungsteil Asva F (nach Lõugas 1970a, Beilage; modifiziert dargestellt).

Weniger eindeutig im Befund niedergeschlagen als die Steinfußböden einstiger Hausbauten haben sich die Umrisse der den Siedlungsabschnitt begrenzenden Mauer. Die Reste einer 1,3-1,5 m breiten Trockenmauer aus Schieferplatten kamen bereits in Asva A und E zum Vorschein. Dort fällt allerdings die stratigraphische Zuweisung zu den Siedlungsphasen schwer, weil sich der Mauerstreifen im Befund nicht immer als solches zu erkennen gibt bzw. in den Zeichnungen nicht von den angrenzenden Steinstrukturen (Bodenpflasterung) zusammenläuft (Asva A). Im Nordteil (Asva E) wurde die Steinmauer, den Befund- und Profilzeichnungen nach zu urteilen, offensichtlich stehen gelassen. Man hat in der Folge (1949er Kampagne) nur in deren Innenbereich gegraben. Man kann also nur die nicht überprüfbaren Bemerkungen der Ausgräber zur Kenntnis nehmen, wonach die Mauerzüge auf dem anstehenden Boden gründen und verschiedene Bauphasen erkennen lassen sollen. ${ }^{29}$

Im Grabungsteil Asva F konnte Lõugas ebenfalls die Fundamentreste einer solchen Siedlungsbegrenzung beobachten. In Umrissen lässt sich aus der Anordnung der Kalksteinplatten ein Mauerzug von 1,5-1,7 m Breite ablesen, dem natürlich vorgegebenen Verlauf der Geländekante folgend (Abb. 9). Er bestand nur teilund ansatzweise, weil er vermutlich von späteren, burgwallzeitlichen Eingriffen und Umbauten gestört wurde (Lõugas 1970a, 357 f.). Aus den Befundzeichnungen und Profilplänen geht indes hervor, dass die steinerne Umfassung nicht von Beginn

${ }^{29}$ Indreko 1938, 3 f.; Vassar 1948, 7; 1955, 116. 

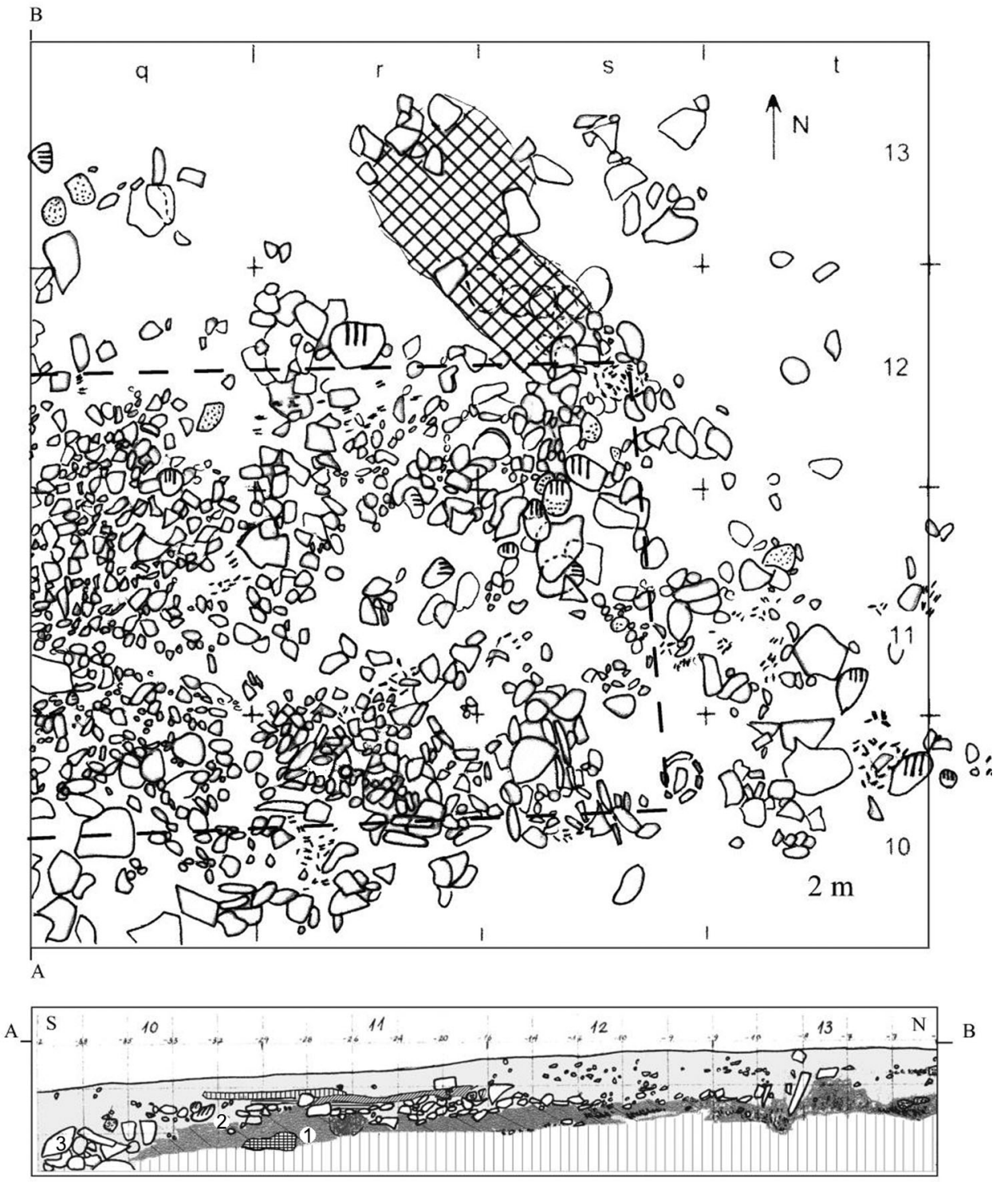

Abb. 10. Plan und Profil vom Befund E (nach Lõugas 1965, Plan 17; 1970a, Beilage; Sperling 2006, Abb. 6). 1 Kulturschicht Asva I mit Brandspuren, 2 Steinplatten- und Laufhorizont von Haus E (Asva II), 3 Steine der Trockenmauer (und Burgbergschicht); Schraffur: Rohlehmpackung.

an, d. h. mit der Phase Asva I, bestanden haben kann. Auch stellte Lõugas fest, dass sie im Ostteil den Bereich des im Befund (Stampfboden, Brandreste) gut sichtbaren Wohnbaus D schneidet. Brand- und Kulturschicht des Hauses verlaufen sichtbar unterhalb der Steinmauer nach Osten weg, der Steinzaun (kivitara) kann folglich erst in der nächsten Siedlungsperiode errichtet worden 
sein (1970a, 337; siehe unten). Daraus ließe sich nur schlussfolgern, dass Asva nicht in allen Phasen der Besiedlung und nicht von allen Seiten umfriedet war. ${ }^{30}$

\subsubsection{Asva F: Häuserhorizont B/D (Asva I)}

Nach Abtrag der Steinpflasterung (Haus E) kam noch im Grabungsjahr 1965 der Hausgrund B mit Resten eines Gießerplatzes zutage. Der mit B benannte Befund konnte indes erst im Folgejahr vollständig untersucht werden. Unter der dünnen Brandschicht kamen Hüttenlehm und große Mengen an Keramik und Gussformen zum Vorschein. Steine wurden mit zunehmender Grabungstiefe immer weniger. Im nächsten Planum, unter der Steindecke und der partiell auftretenden Lehmdecke, hob sich durch seine Dunkelfärbung ein rechteckiger Hausgrund vom helleren, anstehenden Boden ab (Abb. 11). An einigen Wand- und Eckbereichen sind im Planum dunkle, mutmaßliche Pfostenfärbungen sichtbar, die aber nicht untersucht oder dokumentiert wurden. Die Wandverläufe werden an einigen Stellen von länglichen Lehmeinträgen und Granitsteinen begleitet. Somit werden die Umrisse eines ca. sechs mal vier Meter in Länge und Breite messenden, West-Ost ausgerichteten Hauses gut sichtbar. Lõugas beschrieb den festen und dunkelbraun-schwärzlichen Boden als eine Art Trampelschicht (Lõugas 1966a, 25). Im Hausinnern kam eine Herdstelle mit Lehmboden und Lehmmantel zutage sowie zahlreiche gebrannte Hüttenlehmstücke. Die Ostwand liegt jenseits der Grabungsgrenze, doch hat es den Anschein, dass mindestens zwei Drittel des länglichen Rechteckbaus erfasst wurden. Auf den südlich des Hauses B vorgelagerten Bereich mit reichlich Spuren von Metallgusstätigkeit wird an späterer Stelle detaillierter eingegangen.

Ein anderer, mit D bezeichneter Hausgrund kam 1966 nach Abtrag der zum Hauskomplex C gehörigen Steindecke zutage. Große Teile des in einem Brand zerstörten Wohnbaus wurden von einer kompakten Lehmschicht (14-15/õ-ä), eine Fläche von ca. $10 \mathrm{~m}^{2}$ einnehmend, überlagert. Im Nordprofil (Abb. 12) sind die wohl zum Zweck der Planierung aufgetragene, bis zu zwanzig Zentimeter dicke Lehmschicht und der darunter liegende asche- und holzkohlehaltige Brandhorizont gut erkennbar. Diese 10-15 cm dicke Brandschicht trat direkt unter der östlichen Seite des Hauses C ab einer Tiefe von $130 \mathrm{~cm}$ (vom Festpunkt) in Erscheinung. Die Keramik aus dieser Schicht zeigt starke Brandspuren (Lõugas 1966a, 28). Im Planum sind mehrere Asche- und Holzkohlenester verstreut, einige rundliche Einfärbungen könnten von Wandpfosten (Giebelwand?) herrühren. Im Westteil des Planums sind lose verteilte Kalksteinplatten eingetragen, die offensichtlich der jüngeren Siedlungsphase angehören (Einfriedung). ${ }^{31}$ Auch bei dem Hausgrund D handelt es sich um einen gestampften Erdfußboden (Lõugas 1966a, 31)

30 Die Ausgräber selbst rekonstruierten nur brusthohe Steineinfriedungen bzw. Umzäunungen (ca. 1,5 m Höhe), in Analogie zu den noch heute auf Saaremaa anzutreffenden Gehöft- oder Weilerumgrenzungen (Vassar 1955, 116 f.; Moora 1967).

31 Das bestätigen die im Plan eingetragenen Höhenwerte (Lõugas 1966a, Plan 10). Siehe auch das Profil der Nordwand (gleichzeitig Grabungsgrenze): Dort gibt sich eine Herdstelle zu erkennen, die jedoch an keiner Stelle dokumentiert wurde, aber die steinerne Einfriedung kreuzt. 


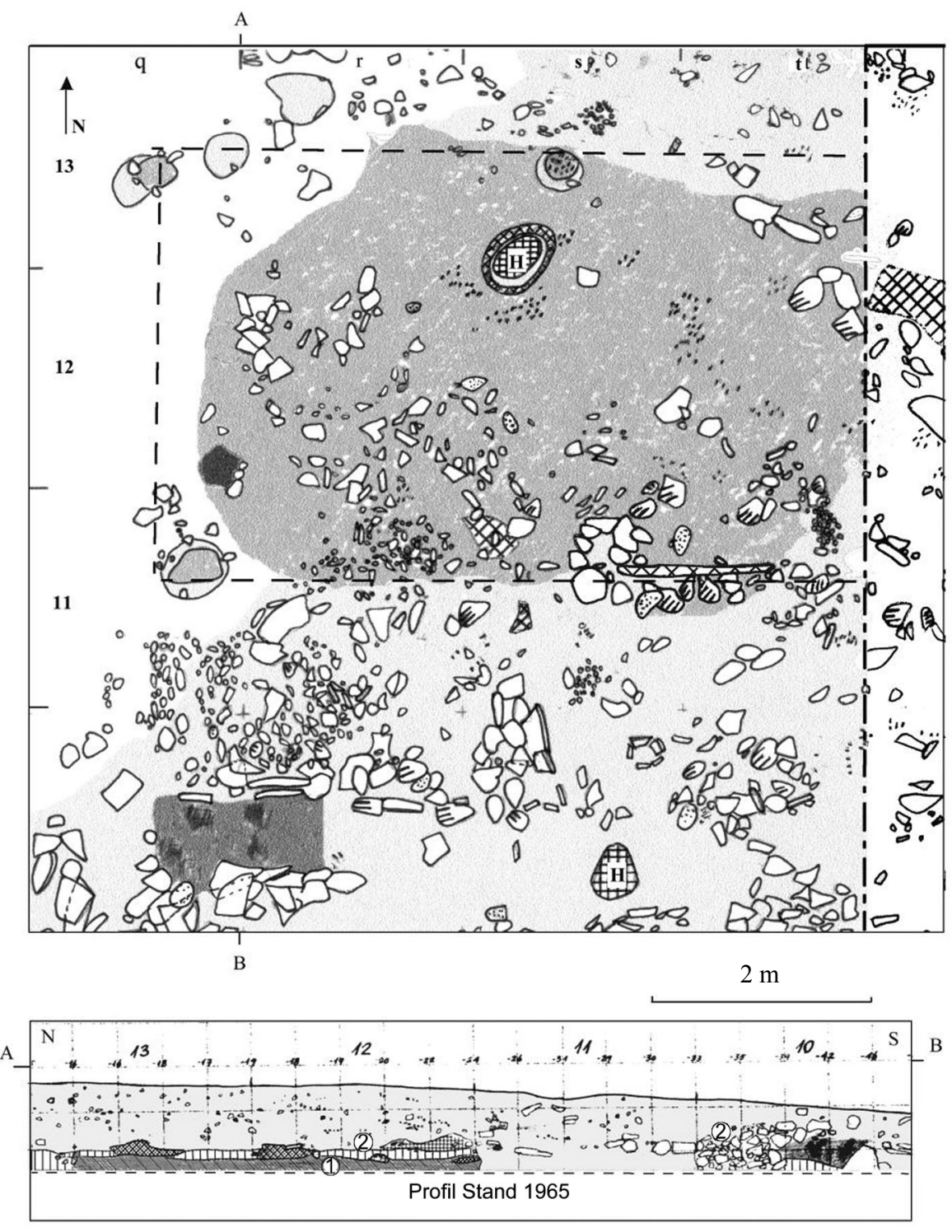

Abb. 11. Plan und Profil vom Haus B (nach Lõugas 1965, Plan 17; 1966a, Plan 7, 9; Sperling 2006); H - Herdstellen. 1 Fußbodenbereich des Hauses B (Asva I), zum Gießerplatz gehöriger ,Rußkasten“ mit Asche- und Holzkohle (Asva I), 2 Schicht Asva II mit Lehm und Resten der Steinpflasterung des Hauses E (Asva II). Schraffuren: gebrannter Rohlehm.

mit den Haus B ähnlichen längsrechteckigen Konturen in West-Ost Ausrichtung. Die einstigen West- und Südwände werden durch einige größere Schieferplatten flankiert, die mit dichtgepackten kleinen Kieseln und Steinschutt Reste eines mutmaßlichen Pflasterwegs und Eingangsbereichs darstellen (vgl. Haus B). Die Lage der von der Grabungsgrenze abgeschnittenen Ostwand ist nur annähernd 

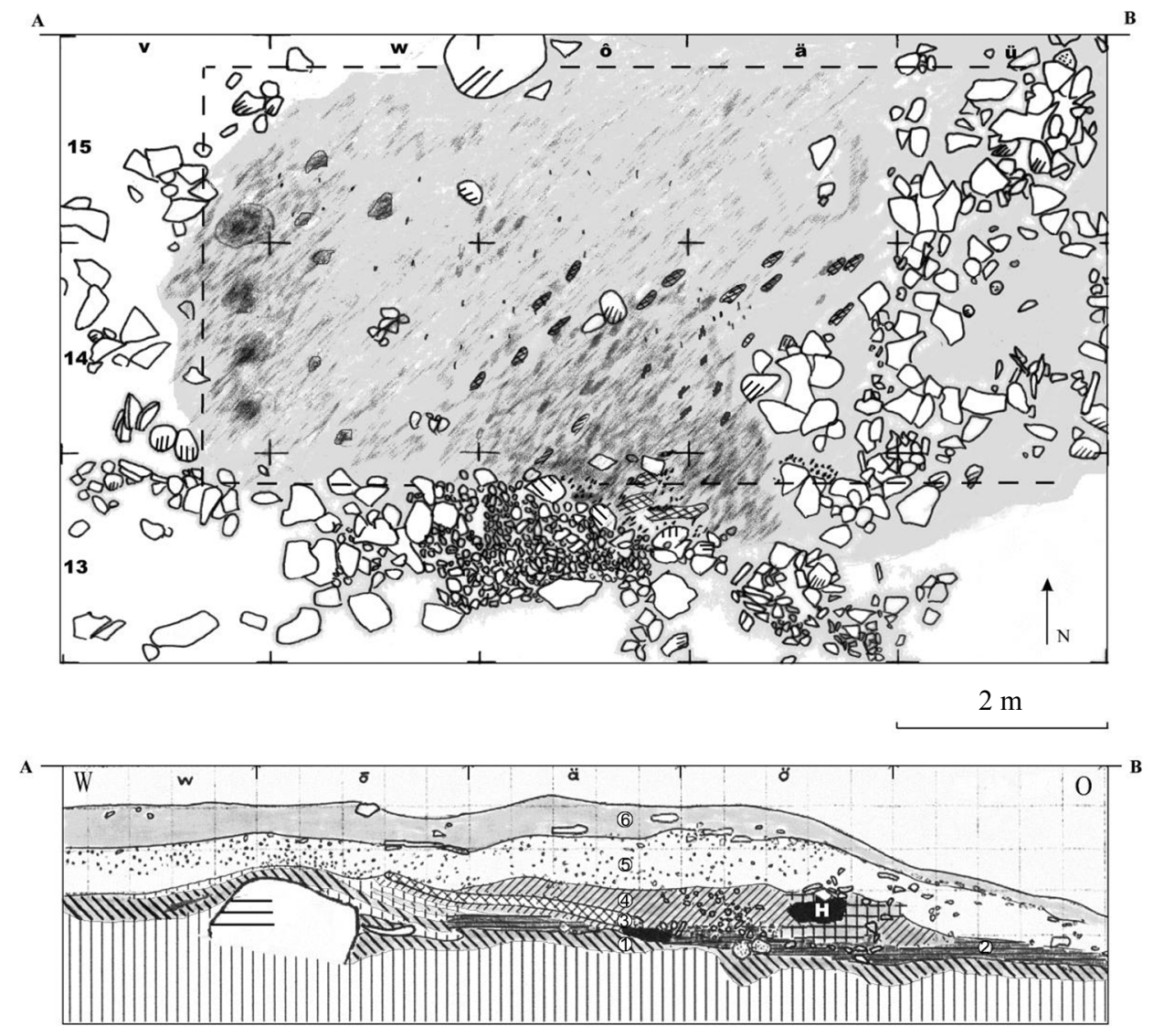

Abb. 12. Plan und Profil vom Befund $D$, nach der Originaldokumentation (modifiziert) (nach Lõugas 1966a, Plan 10-11; Sperling 2006, Abb. 8). 1 Schicht Asva I, 2 Brandschicht mit Asche, Holzkohle und feuergeschädigter Keramik, 3 Planierungsdecke aus Lehm, 4 Schicht Asva II mit Herdstelle (H), 5 ,sterile' Zwischenschicht, 6 pfluggestörte Schicht Asva III (,Burgberg').

lokalisierbar. Immerhin ließe sich aus den Umrissen des Erdfußbodens ein vergleichsweise großflächiger Wohnbau rekonstruieren, mit Maßen von ca. $4 \times 6-8$ Metern. Hüttenlehm und Hinweise auf Metallguss gab es im Bereich von Haus D keine.

\subsubsection{Brandnachweise}

Die gute Erhaltung der Hausstrukturen und der Siedlungsfunde, z. T. in geschlossenen archäologischen Kontexten, gehen größtenteils auf deren Konservierung durch die Brandschichten zurück. In den Ausgrabungsberichten für Asva F wird eine zentimeterdicke Schicht mit Holzkohle, Asche und stark feuer- bzw. hitzegeschädigter Keramik erwähnt, welche der Siedlungsphase der Häuser B und $\mathrm{D}$ angehört. Besonders im Ostteil von Asva F, eine Fläche von über $35 \mathrm{~m}^{2}$ 
einnehmend, werden die Brandschäden sichtbar (Lõugas 1965, Plan 13-14; 1966a, 25 f., Plan 9). In der Kartierung von eindeutig intensivem Schadfeuer ausgesetzter Gefäßkeramik (blasige, geschwärzte Oberfläche) im Grabungsteil Asva F kommt eine räumliche Konzentration im Mittelbereich des Hauses D zum Vorschein. Eine weitere Verdichtung der Keramikscherben mit sekundären Feuerschäden gibt es im Haus B (Abb. 13).

Auch die Hausbauphase A/C/E (Asva II) soll von einem Schadfeuer betroffen gewesen sein, Brandspuren sind dort vereinzelt nachgewiesen. Aus einem Holzkohlenest des steingepflasterten Hauses E, es soll sich um Reste verkohlter Pfosten handeln, wurden vom Ausgräber Proben für ${ }^{14} \mathrm{C}$-Datierungen entnommen (Lõugas 1966a, 3 f.; 1970a, 346).

Im Grabungsteil Asva A hat der Brandschutt die Reste verkohlter Balkenbauten konserviert (Indreko 1938, 4, Abb. 4; 1939b, 3 f., Abb. 1) und im Nordteil E wurde ein hoher Anteil an Ascheresten und Holzkohle, ebenfalls in der älteren Siedlungsphase (wie Asva F), bemerkt (Vassar 1948, 8, 13, 18 f., 23 f.). Es hat demnach den Anschein, dass die ganze Asva-Siedlung mindestens einer Brandkatastrophe zum Opfer fiel.

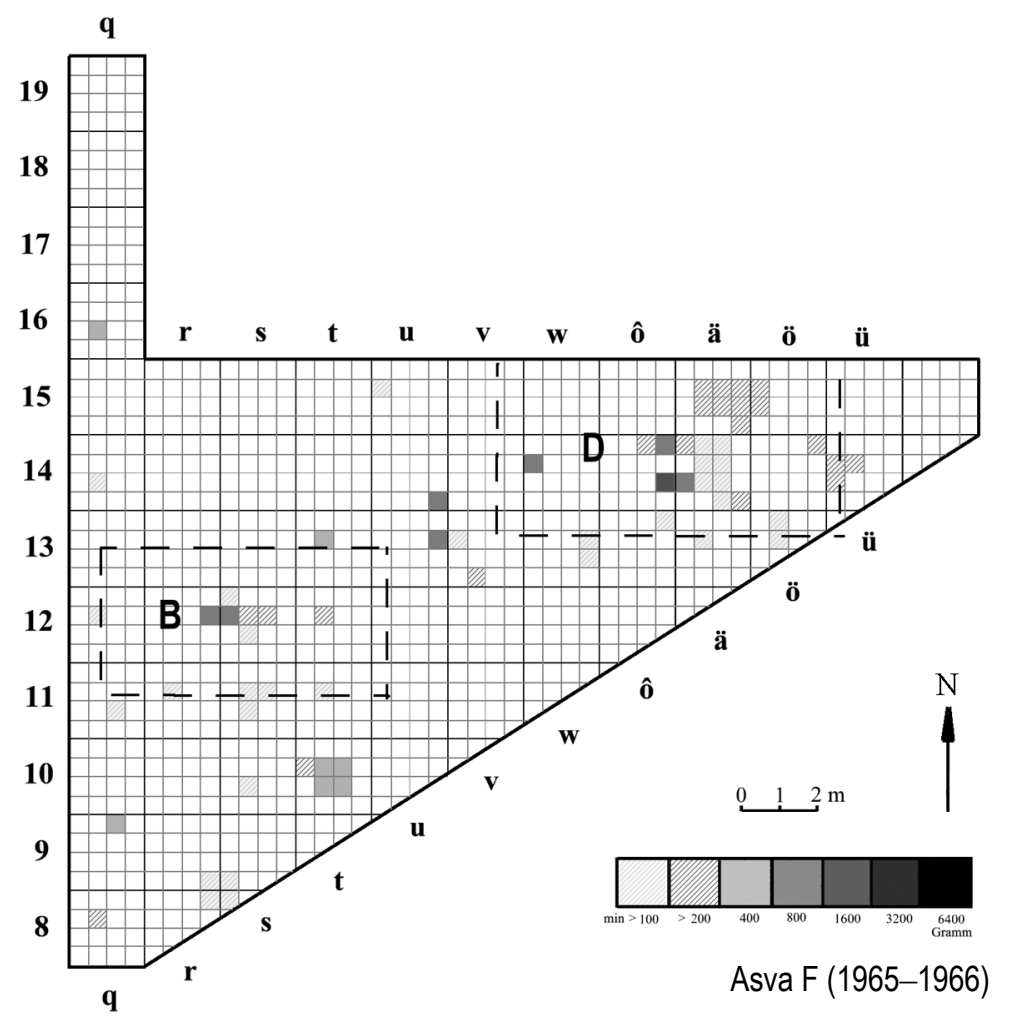

Abb. 13. Gewichtsverteilung der Gefäßscherben mit intensiven Feuer- und Hitzespuren im Grabungsteil Asva F. 


\subsection{Ridala}

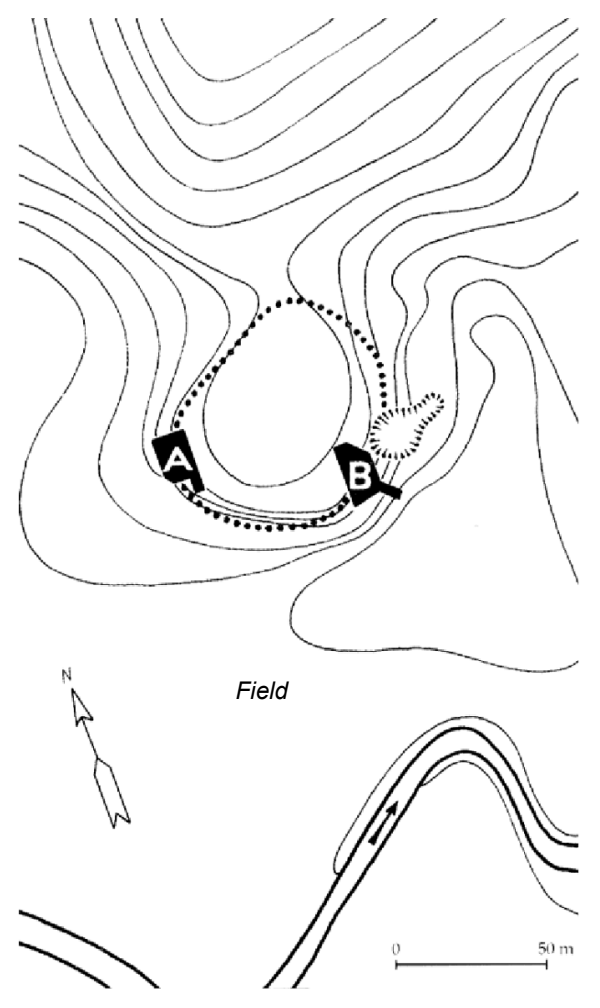

Abb. 14. Der Fundplatz Ridala mit den beiden Grabungsflächen.
Der Fundplatz liegt ca. fünf Kilometer nördlich von Asva auf dem gleichen Moränenzug. In der Spätbronzezeit wird diese Landerhebung zu ca. zwei Dritteln von Wasser umgeben gewesen sein. Heute ragt das Siedlungsplateau (ca. $4000 \mathrm{~m}^{2}$ ) noch anderthalb Meter im Gelände hervor. Die archäologischen Untersuchungen, insgesamt drei Grabungskampagnen, konzentrierten sich auf den westlichen und östlichen Grenzwall (Abb. 14). Alles in allem kann nur ca. ein Zehntel der Anlage als erforscht gelten (insgesamt $435 \mathrm{~m}^{2}$ Grabungsfläche). Bemerkenswert sind die Untersuchungsergebnisse, zumal aus Ridala fast ausschließlich Siedlungsfunde der Spätbronzezeit und Befunde einer interessanten Doppelpalisade zutage kamen. Doch ist die Grabungsdokumentation spärlich und mangelhaft, ein offiziell verfasster Bericht zu den Untersuchungen liegt nicht vor. Zeichnungen der Plana und Profile gibt es, nur sind diese lediglich mit Hilfe der handschriftlichen Tagebuchnotizen der Ausgräber auswertbar. Zwar sind die Palisadenstrukturen in der Literatur wiederholt erwähnt und diskutiert worden. Eine kritische Reflektion der verfügbaren Fakten zur archäologischen Befundaufnahme und -situation hat bislang noch nicht stattgefunden. Im Zuge der Vorarbeiten dieser Untersuchung, d. h. der Sichtung der Materialien und Aufzeichnungen, ergab sich, nämlich die Siedlungsabfolge und Palisadenbauten betreffend, ein gewisser Diskussionsbedarf. Im Folgenden sollen in Kürze die Befunde (Palisaden, Wohnbauten) vor dem Hintergrund ihrer Entstehungsprozesse vorgestellt werden.

In Ridala hat man Reste von Palisadenkonstruktionen festgestellt. Eine derartige Befestigungskonstruktion, insofern es sich tatsächlich um solche handelt, ist bislang im gesamten nördlichen Ostbaltikum dieser Zeitperiode und darüber hinaus einzigartig. Unter den bekannten und untersuchten Siedlungen der Spätbronzeund Früheisenzeit Lettlands sind zwar mehrere Wallanlagen und Palisadenbauten, doch sind diese nicht direkt mit denen von Ridala vergleichbar. Was den hiesigen Fall besonders hervorhebt, sind besonders zahlreichen Pfostengruben, die sich im Grenzbereich der Siedlung in einer Art Kranz um die Siedlung ziehen und deren Funktion bislang nur in Ansätzen diskutiert wurde. Der Befestigungscharakter 
Ridalas und zahlreiche Pfeilspitzenfunde gaben bereits früh Anlass zur Hypothese, die Siedlung könnte akuten Bedrohungen von außerhalb ausgesetzt gewesen sein und ihr Ende letztendlich in einem Angriff oder Überfall gefunden haben. Die Thematik vom Überfallszenario und der fortifikatorischen Disposition der Siedlung wurde an anderer Stelle ausführlicher diskutiert (Sperling \& Luik 2010).

Wie bereits erwähnt, lässt sich in der Interpretation der Grabungsbefunde von Ridala (Palisaden, Häuser) auf keine Grabungsberichte zurückgreifen. Bei der Erörterung und Deutung der Befundlage sind zumindest die Zeichnungen und Skizzen der archäologischen Befunde hilfreich. ${ }^{32}$ Einige Ergebnisse der Kampagnen 1961-1963 wurden von H. Moora vorgestellt, und zwar im Rahmen der Überblicksdarstellung zum damaligen Forschungsstand zu den sog. Burgbergen im Ostbaltikum (1967). Moora fügt seinem Artikel auch einen Grabungsplan von Ridala A und B bei. Dort sind die Pfostengruben, Steinstrukturen und Brandstellen mitsamt den Höhenlinien des Siedlungsgeländes vom sog. Burgberg eingetragen (Abb. 15).
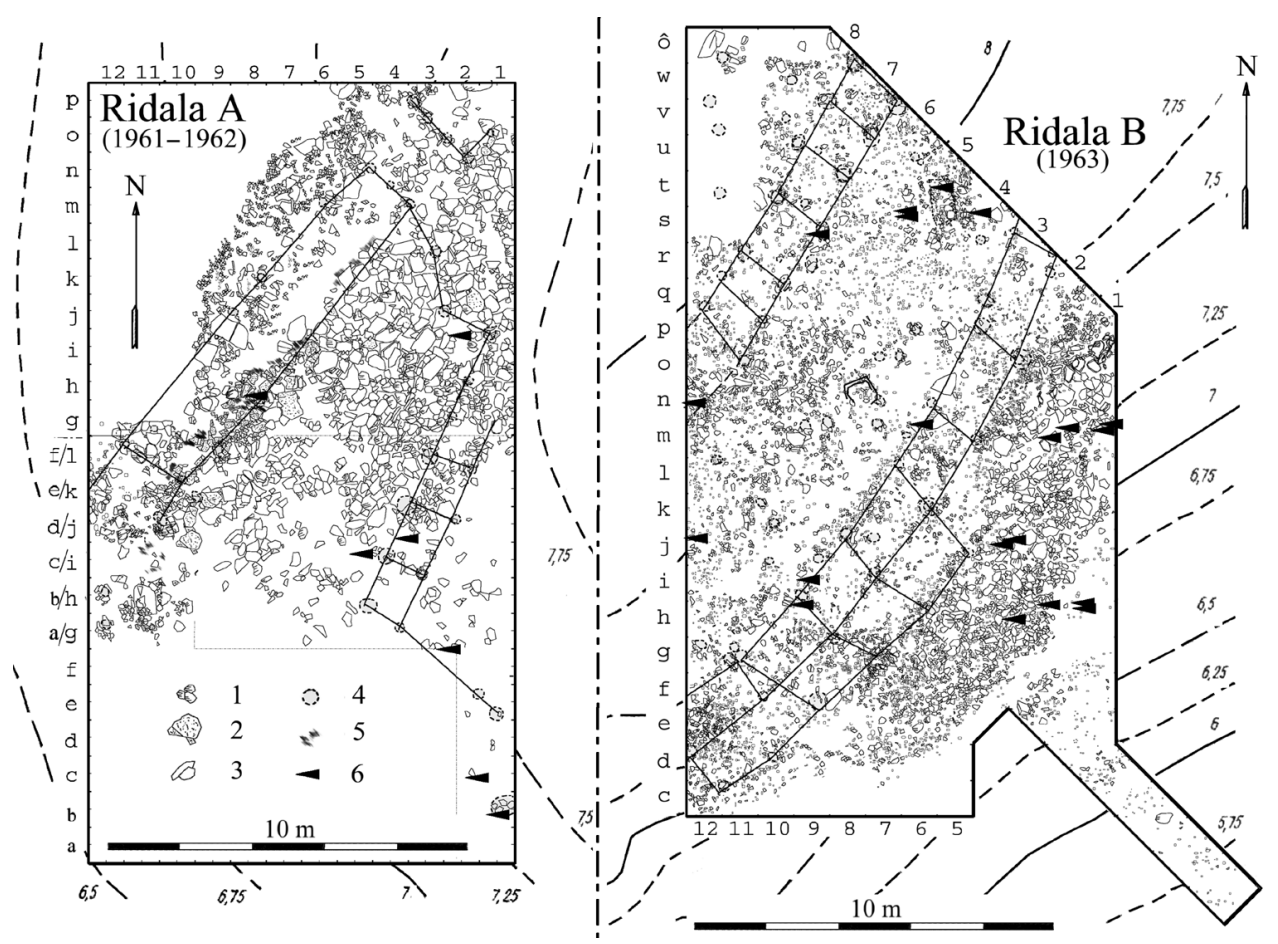

Abb. 15. Grabungsplan von Ridala (nach Kustin 1961; Vassar 1962; 1963). 1 Feldsteine, 2 Kalkstein mit Feuereinwirkung, 3 Kalksteintrümmer, 4 Pfostengrube, 5 Holzkohle, 6 Knochenpfeilspitzen.

32 Auch V. Lõugas bezieht sich in seiner Untersuchung auf die Grabungstagebücher (estn. Kaevamispäevikud) von A. Kustin und A. Vassar (Lõugas 1970a, 349, Anm. 1). Die handschriftlichen Notizen sind zwar teilweise schwer lesbar, aber enthalten meist brauchbare Beobachtungen zu den Befunden und zum weiteren Grabungsverlauf. 
Die Bodenverfärbungen der Pfosten (dort schwarz markiert) lassen klare in Fluchten von NO nach SW verlaufende Doppelreihen erkennen. Für den Grabungsteil Ridala A sind 28 Pfostengruben dokumentiert, für das flächenmäßig größere Areal Ridala B ca 53. Die auf diesem Plan ebenfalls eingetragenen Bebauungsspuren (Herde, Steinplatten) im Innenbereich der Pfostenreihen zeigen, dass der Charakter der Siedlungsbegrenzung nicht nur ein rein fortifikatorischer gewesen sein mag. Zudem weisen die Wohnbauten und Siedlungsreste von Ridala A und B untereinander signifikante Eigenheiten und Unterschiede auf, die erst noch erörtert werden müssten. In den Grabungstagebüchern von Kustin und Vassar finden sich nur wenige Kommentare zum Verlauf der Pfostenreihen im Gelände.

\subsubsection{Die Palisaden}

\subsubsection{Ridala A}

In der Ersterwähnung der Pfostenanlagen durch H. Moora ist von zwei Umzäunungen die Rede (Moora 1967, 68). Es gibt eine innere und eine äußere Wand, getrennt durch einen 5-6 m breiten Zwischenabstand. Der bogenförmige Verlauf orientiert sich am Rand des Siedlungshügels, entlang der Landerhebung. Moora vermutete, dass die Pfosten sowohl zu ,Umzäunungswänden' als auch zu ehemaligen Wohnbauten gehörten, welche sich anhand von Herdstellen und Pflasterungen von Kalksteinfliesen zu erkennen geben (Abb. 16-17). Auf den Sinn und Zweck dieser merkwürdigen, doppelten Pfostenkonstruktion wurde aber nicht weiter eingegangen.

Von der Existenz einer Siedlungsbefestigung zeugen einzig und allein die während der Ausgrabung gut erhaltenen und sichtbaren Pfostenlöcher, und zwar in den beiden Siedlungsarealen. Insgesamt beläuft sich die Zahl der leider nur unzureichend dokumentierten Gruben auf über 80. Von Balken oder Holzschalenwänden eines mutmaßlichen Palisadenbaus sind keine erhalten.

Verlauf und Anordnung der Pfosten sprechen für eine systematische Planung und Ausführung der Siedlungsbegrenzung. In Ridala A sind ca. 28 solcher Gruben ausgemacht worden. Leider wurde die Dokumentation dieser vernachlässigt, so dass die meisten nur im Planum zeichnerisch erfasst wurden. Profilschnitte durch diese Gruben und begleitende Beschreibungen liegen, bis auf zwei Ausnahmen, sonst keine vor. Wie aufschlussreich allerdings die Aufnahme sämtlicher Gruben gewesen wäre, zeigen jene beiden Pfostenbefunde (Abb. 18). Sowohl im Durchmesser als auch in der Tiefe sind diese voneinander gänzlich abweichend und hinweisgebend auf die Größe und Beschaffenheit der jeweils verwendeten Pfostenhölzer. Ein U-förmiges, trichterartiges Profil mit kaum ausgeprägtem Boden zeugt von einem ca. 20-30 cm dicken und leicht angespitzten Stamm. Die andere dokumentierte Pfostengrube ist ca. $60 \mathrm{~cm}$ breit, kesselförmig und vergleichsweise flach in den Boden eingetieft. Beide Pfosten zeugen also von sehr unterschiedlicher Gestalt und Funktion, wobei nicht festzustellen ist, wo diese im Haus- oder im Palisadenbau eingesetzt wurden. 


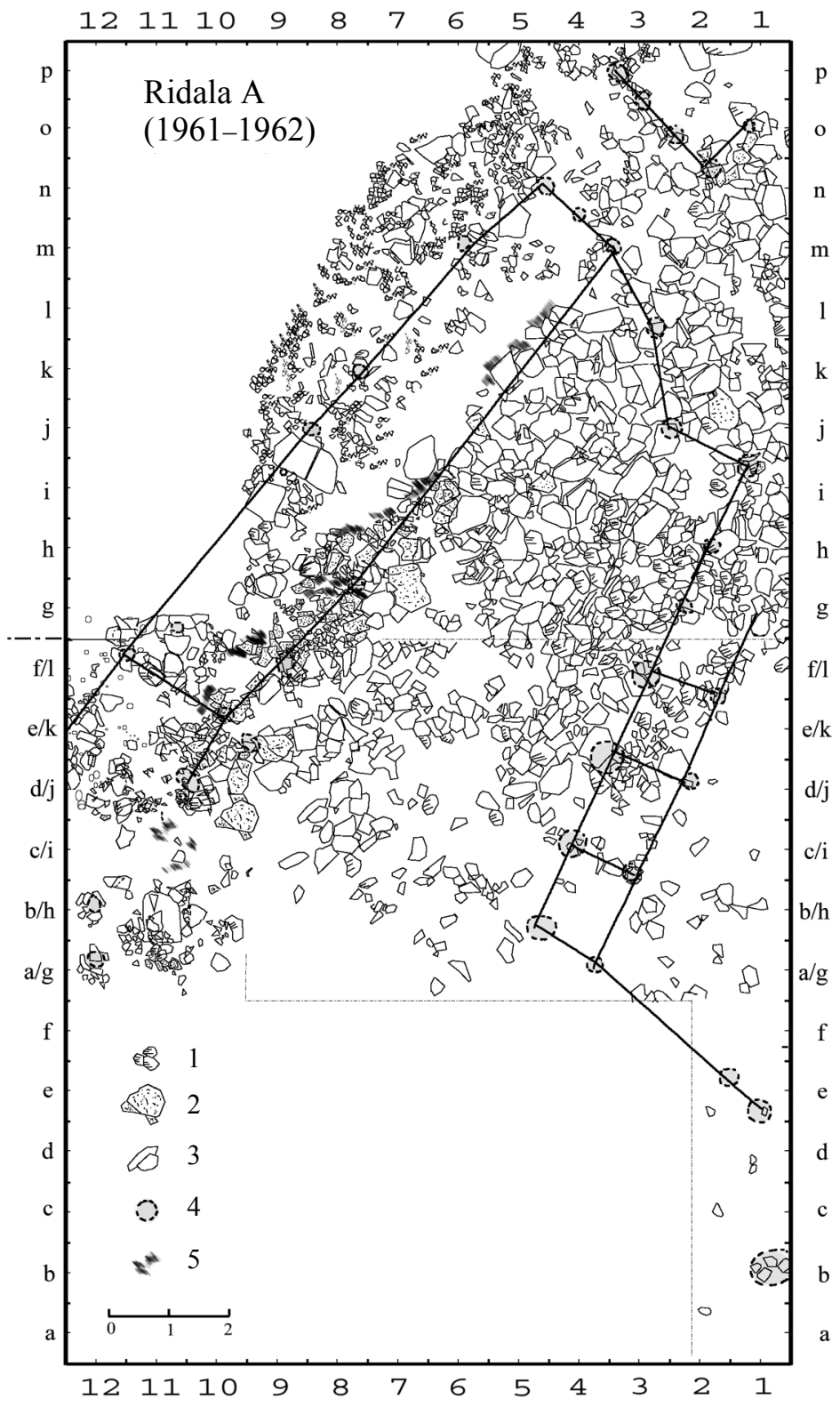

Abb. 16. Ridala A (nach Kustin 1961, Pl. 2, 5-6; Vassar 1962, Pl. 4-6). 1 Feldsteine, 2 Kalksteine mit Feuereinwirkung, 3 Kalksteintrümmer, 4 Pfostengrube, 5 Holzkohle. Die Konturen/Verbindungslinien der Pfosten wurden nachgezeichnet.

Auch aus der Verteilung der Pfostengruben im Gelände lassen sich gewisse Strukturen erkennen. Im Ostteil von Ridala A sind diese in zwei parallelen Reihen, in Richtung SW-NO, angeordnet. Die Pfosten jeder Reihe sind mit Abständen von $2 \mathrm{~m}$ auf die gegenüberliegenden ausgerichtet, ergeben bei Verbindung 


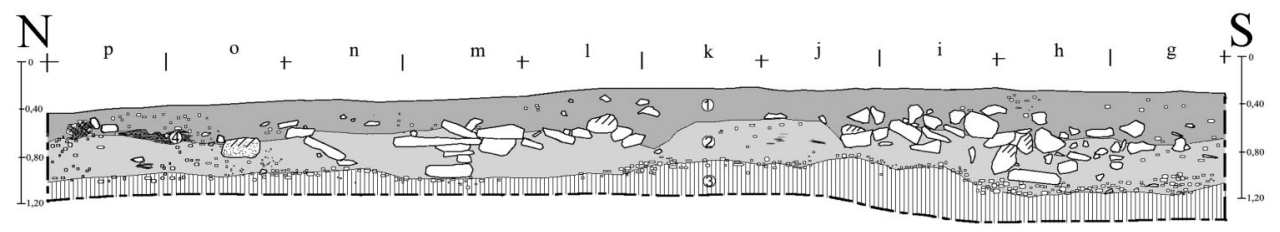

Abb. 17. Ridala A: Ostprofil des nördlichen Grabungsteils (nach Vassar 1962, Pl. 8). 1 dunkelbrauner Humus mit vereinzelten Brandspuren, Oberteil durchpflügt, 2 hellbraune Kulturschicht, unterläuft Hausbodenniveau, 3 anstehender Moränenboden mit Strandkies, 4 Brandreste.
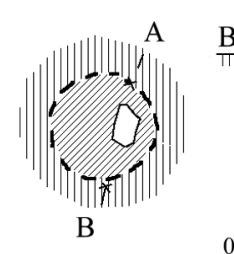

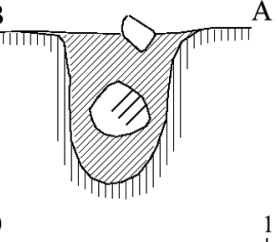

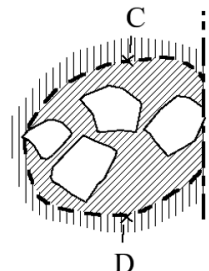

D

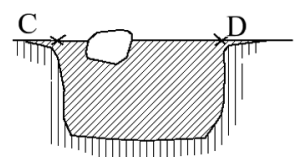

Abb. 18. Zwei Pfostenprofile aus Ridala A (nach Kustin 1961, Pl. 2); A-B: Quadr. 1/e; C-D: 1/d.

aneinandergereihte rechteckige Strukturen. Die Anordnung der Pfosten ist demnach nicht zufällig, sondern systematischer Natur mit zwei Wandverläufen und zwischenliegenden, fast quadratischen Kammern. Im Westteil, ungefähr in 6 m Distanz zu dieser Doppelreihe, sind weitere Pfostenreste aufgetaucht, wieder in Reihen nach NO verlaufend. Die Anzahl der erkannten Gruben in diesem Bereich ist kleiner und unregelmäßiger, scheint jedoch einen ähnlich doppelten Wandaufbau anzudeuten. Der Abstand zwischen den Pfostenreihen ist größer (ca. $3 \mathrm{~m}$ ).

Interessant ist die Pfostensetzung im nordöstlichen Teil von Ridala A. Dort sind 7 Gruben zu 3 und 4 Reihen in einer Art Korridor angeordnet, der den besagten Wandverlauf unterbricht und diagonal kreuzt. Es hat also den Anschein, es könnte sich an dieser Stelle um eine Öffnung der Begrenzung handeln, um ein Art Tor womöglich. Denkbar wäre eine Passage oder ein Einlass, zumindest würden sich so der dichte Aufbau der Pfosten und deren Ausrichtung erklären. Vom defensorischen Standpunkt her betrachtet wäre der Zugang an diesem Platz sinnvoll, da der Knickverlauf der Begrenzung den sich der Siedlung Nähernden zwingt, die Pfostenwand mit seiner rechten, ungeschützten Seite zu umlaufen. Leider bleibt diese Deutung hypothetisch, weil sich der Befund im Bereich der Grabungsgrenze befindet.

\subsubsection{Ridala $B$}

Diese besagten Pfostenreihen sind in Ridala B noch klarer zum Vorschein getreten. Die Mehrzahl der 53 Pfostengruben verteilt sich in ziemlich deutlicher 
Regelmäßigkeit auf fünf Reihen (so auch Lõugas 1970a, 351), vier davon durchziehen die ganze ergrabene Fläche (Abb. 19). Davon gruppieren bzw. paaren sich jeweils zwei Reihen solcher Gruben im inneren Bereich, also im nordwestlichen Teil der Fläche. Die drei übrigen Pfostenstränge umlaufen die äußere Siedlungsgrenze

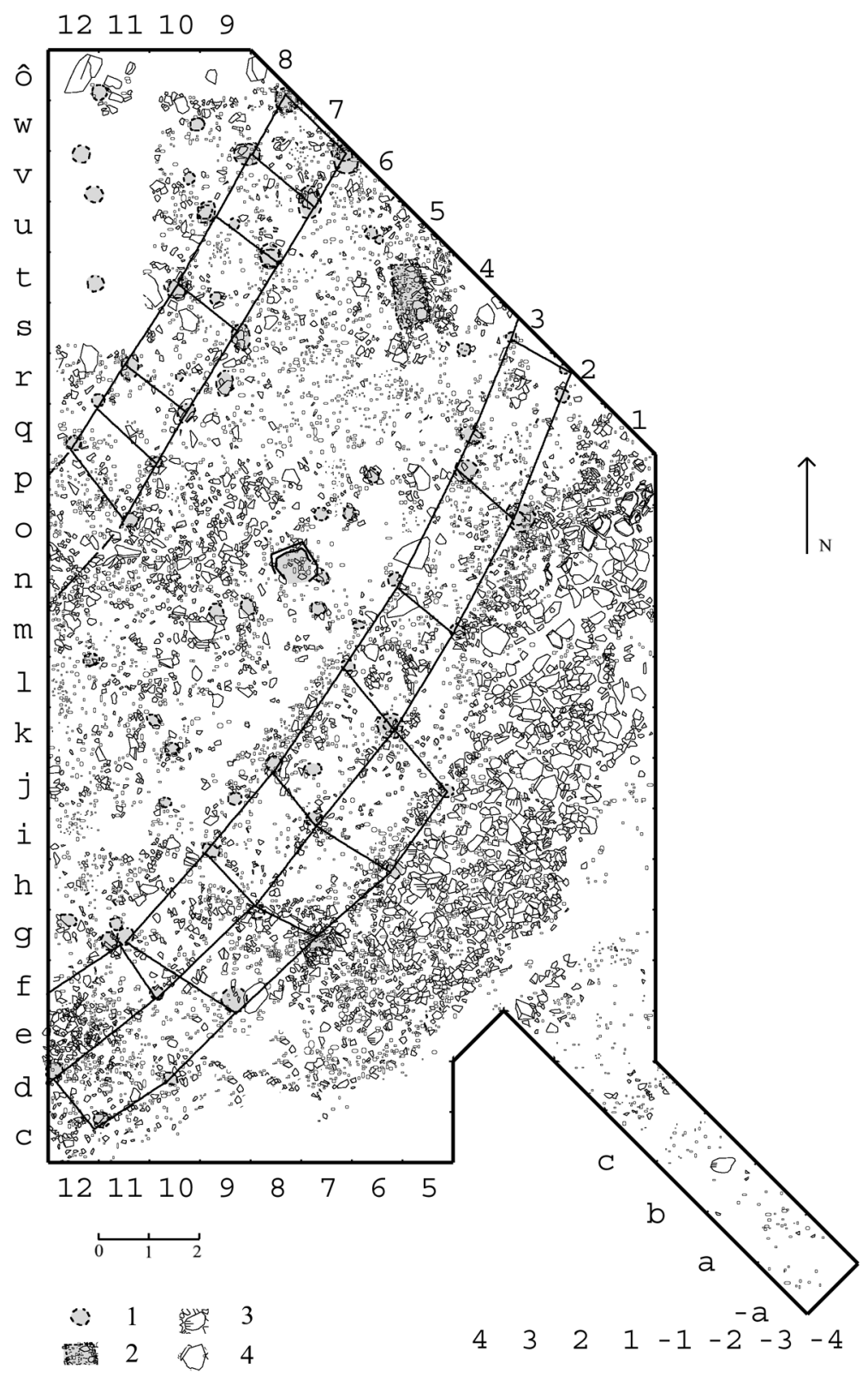

Abb. 19. Ridala B (nach Vassar 1963, Pl. 2-11; Linien ergänzt). 1 Pfostengrube, 2 Herdstelle, 3 Feldsteine, 4 Kalksteinplatten oder -trümmer. 
(Südosten der Fläche), wobei die äußerste (dritte) Reihe von einer länglichen, streifenartigen Steinsetzung unterbrochen wird. Was die Doppel- bzw. Dreifachreihen wiederum auszeichnet, ist deren Paarigkeit der Pfosten (wie in Ridala A). Jeder Pfostengrube einer Reihe ist im Abstand von ca. $2 \mathrm{~m}$ eine weitere, unmittelbar gegenüberliegende zugeordnet. Die Intervalle zwischen den Pfostenpaaren des äußeren Strangs sind größer, bis zu $4 \mathrm{~m}$, als jene des Inneren (ca. $2 \mathrm{~m}$ ). Bei Verbindung der entsprechenden Pfostenpaare ergibt sich eine zweifache Kettenstruktur aus rechteckigen Gliedern, die sich schienenartig um das Siedlungsinnere herum und an der Terassierung entlang zieht. Bemerkenswert ist der nur von einigen unregelmäßig verteilten Pfosten gesäumte Innenraum, der beide Postenwände in einem Abstand von ca. 6 m trennt. Dort verteilt sich ein Großteil der Siedlungsfunde und einige Feuer- und Herdstellen.

Die Ausmaße der Pfostengruben schwanken zwischen 20 und $40 \mathrm{~cm}$, sie wurden allerdings nicht alle in einem Zuge oder in einem Tiefenniveau aufgenommen und dokumentiert. Wie im Ostteil A fehlt es an Einmessungen und Zeichnungen der Pfostengruben, bis auf einzelne Ausnahmen gibt es keine Profildarstellungen der Pfosten. Dieser Umstand schränkt die Beurteilung der gesamten Anlage enorm ein. Dass es sich jedoch mit Sicherheit um Pfostengruben handelt, geht aus der Beschreibung ihrer Gestalt und ihres Inhalts im Grabungstagebuch und aus den zeichnerischen Farbdokumentation hervor. Meist ist aus den Berichten nur zu erfahren, dass es sich um Pfostengruben mit vertikalen oder schrägen Wänden handelt. In Ridala B wird allerdings ausdrücklich auf Besonderheiten bezüglich der Lage und Ausrichtung der Pfosten hingewiesen. Mindestens zwei im Bereich der südlichen Wandreihe $(7 / \mathrm{i} \mathrm{NW} ; 8 / \mathrm{j})$ werden als schräg eingetieft beschrieben. Demnach sollen diese deutlich nach innen geneigt haben, d. h. in Richtung NW (Vassar 1963, 28). Die Lage und Stellung dieser Schrägpfosten könnte auf deren besondere Stützfunktion an der Außenwand weisen.

In der Profildarstellung der nordöstlichen Grabungsgrenze von Ridala B ist der innere Pfostenkranz erfasst. Beide Pfosten mit einem Zwischenabstand von zwei Metern sind gut sichtbar und bis zu $50 \mathrm{~cm}$ tief unter der bräunlich-humosen Kulturschicht im anstehenden Moränenboden eingebracht (Abb. 20).

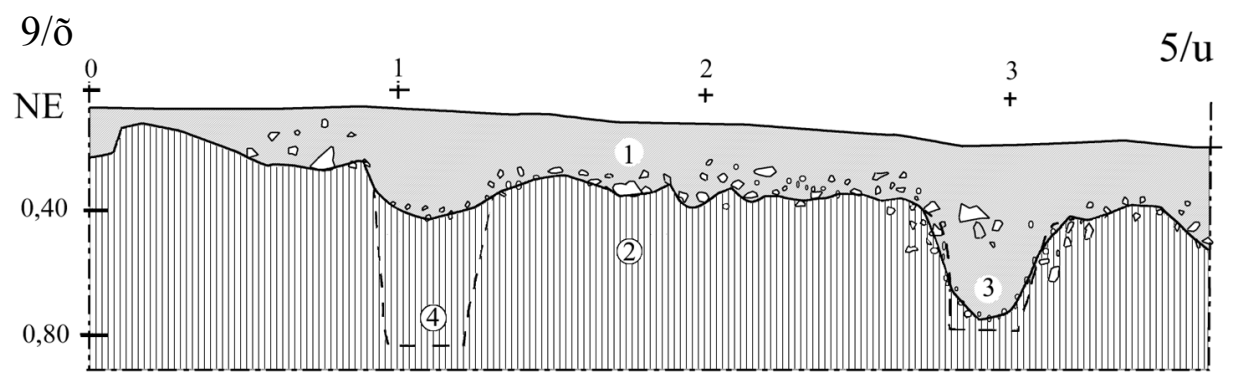

Abb. 20. Ridala B: Ausschnitt des Ostprofils mit Pfostengruben (nach Vassar 1963, Pl. 13). 1 bräunliche, humose Kulturschicht, 2 anstehender Moränenboden mit Strandkies, 3 trapezförmige Grube, angefüllt mit Kulturschicht, 4 Konturen einer trapezförmigen Grube. 


\subsubsection{Aufbau und Zusammensetzung der Palisaden}

Aus dem Verlauf der Pfosten im Gelände und ihrer Beziehung zueinander geht mit großer Wahrscheinlichkeit hervor, dass diese zu einer die Siedlung umlaufenden und begrenzenden Anlage gehörten. Zu solch einer Konstruktion, die zunächst nur fortifikatorischen Charakter bedeutet haben kann, sind bis auf die Pfostengruben allerdings keine weiteren Befunde oder Indizien erhalten. Es gibt laut Fundbericht keine Hinweise auf etwaige Pfosten, Balken oder Wandreste. Wie sich zeigt, sind es vor allem die letzteren, die den eigentlichen Anteil an erhaltenen Holzresten (mit Verkohlungen etc.) ausmachen (siehe unten). Von etwaigen Palisaden, Umfassungswänden oder dergleichen zeugen einzig und allein die Pfostengruben.

In der Literatur gibt es zur Ridala-Siedlung und dem eigentlichen Aufbau sowie der technischen Ausführung der Pfostenanlage nur sehr allgemeine Beschreibungen. V. Lõugas (1970a, $352 \mathrm{ff}$.) ist von einer zweifachen Balkenwand ausgegangen (estn. kahekordne puutara; palktara) ${ }^{33}$ Demnach sollen die Pfosten eine zweischalige Mauer aus Holzbrettern o. ä. gestützt haben. Im Westteil B befindet sich jenseits der äußeren Pfostengruppe, entlang der Hanglange, ein ca. zwei Meter breiter Streifen von Steingeröll. Diese Kalksteintrümmer seien Lõugas zufolge entweder als ,Steinversturz' des ehemaligen Palisadenzauns zu deuten (ebd., 353 f.) oder sind ihrerseits Reste eines weiteren Walls, der den Holzzaun einst ergänzte oder verstärkte. Eine Steinmauer solle also die ausgebaute oder verlagerte Partie des Umfassungszauns dargestellt haben (siehe auch Lõugas \& Selirand 1989, 202). Ridalas Befestigungsanlage könne demnach ebenso gut mehrphasig gewesen sein.

Hierbei ist anzumerken, dass man sich bislang einzig und allein auf die von Moora (1967) abgebildeten Pläne der Grabungsareale bezogen hat. Dort hat man ausgewählte Befunde bestehend aus Pfostengruben, Herdstellen und Steinsetzungen hervorgehoben und im Wesentlichen vereinfacht.

V. Lang hat das Palisadenproblem erneut erörtert. Auch er vermutet eine Schalenwandkonstruktion mit 1,5-2,5 m breitem Zwischenraum sowie Pfosten der Vorder- und Rückwand verbindende horizontale Querbohlen. Auch sei davon auszugehen, dass der Zwischenraum der Schalenwände mit Erde und Steinen gefüllt war. Die Steinhäufung am SO-Rand der Siedlung käme als sekundär verlagertes) Füllmaterial in Frage, nicht jedoch als eine separate Steinmauer (nach Lõugas' Theorie) (Lang 2007b, 64 ff.). Alles in allem wird für Ridala von einem ansehnlichen Holzbau ausgegangen, mit Wehrgang oder einer Brustwehr und bis zu drei Meter hohen Außenwänden. Beispiele für ähnliche Konstruktionsprinzipien in Palisadenbauten werden aus anderen Siedlungen der Nachbarregionen angeführt (Brikuİi, Mūkukalns, Ķivutkalns, Narkūnai und Sokiškiai), doch gibt es keinen direkten Vergleich zum Befestigungsbau von Ridala (ebd., 68).

33 In der Literatur zum Palisadenproblem wird stets von einem Zaun oder einer ,Umfassungswand (estn. tara) gesprochen, nicht jedoch von einer Mauer o. ä. Es scheint also gewisse Vorstellungen vom Charakter und der Dimension der Befestigung einer solchen, Wehrsiedlung' gegeben zu haben. 
Der Befund von Ridala offenbart allerdings interessante Gemeinsamkeiten mit dem geschlossenen Palisadenring von Havor auf der Ostseeinsel Gotland. Dort ist der gesamte Platz von einer kreisförmigen Steinumgrenzung umgeben, unter der sich die Reste einer einstigen Doppelpfostenanlage befanden. Die Befestigung der Flachlandsiedlung soll im Zeitraum zwischen Spätbronze- und Vorrömischer Eisenzeit errichtet worden sein (über konventionelle ${ }^{14} \mathrm{C}$-Datierung) (Nylén et al. 2005, 133 ff.). Die Pfostenanlage, als Palisade angesprochen, besteht aus einem Zweifachring aus paarig gegenüberstehenden Pfosten, die zu einem System von kastenartigen Aneinanderreihungen um die gesamte Siedlung angelegt sind. Abstände und Intervalle zwischen Pfostenreihen und Pfostenpaaren entsprechen ganz dem von Ridala. Hinweise auf Wandreste oder verwendete Füllmaterialien fehlen. Von einer umfangreichen Erdentnahme zeugt allerdings der die Siedlung umlaufende Graben (ebd., 102 ff., Abb. 4-5).

Angesichts der Stellung, Anordnung und Dimension solcher Pfostengebilde ist die Deutung der Konstruktion im Sinne erd- und steinverfüllter Palisadenwände die wahrscheinlichste. Aus Mitteleuropa ist das Modell der mitteleuropäischen Pfostenschlitzmauern bekannt, Aufschüttungen von Erde oder von Mauerwerk, die in regelmäßigen Intervallen durch Schlitze für die Stützpfosten unterbrochen werden. Die Konstruktion solcher Wallanlagen wird durch einander gegenüberstehende Vorderwand- und Rückwandpfosten gefestigt, wie etwa am Beispiel des sächsischen „Burzelbergs“, Lkr. Leipzig (Ältere Laténezeit). Dort sind nur die Steinmauern erhalten, allerdings mit den charakteristischen Aussparungen der einstigen Pfosten (siehe Spehr 1981, 20, Abb. 3). Aus spätbronze- und früheisenzeitlichen Kontexten im Gebiet der Lausitzer Kulturgruppen gibt es noch weitere solcher Beispiele. Aus Podrosche, Bez. Cottbus, ist eine mehrphasige Befestigungsanlage bekannt. Der ältere sorgfältiger ausgebaute Abschnitt bestand aus einem Holz-Erde-Wall, bei dem gespaltene Eichenstämme rostartig aufgeschichtet und deren Zwischenräume verfüllt wurden (Erde, Reisig). In einer späteren Phase folgten Plankenwände als Begrenzung, teils zweifach und parallel angelegt und durch paarige Pfosten gestützt (Buck 1982, 98, Abb. 1: D-F). In Ridala kamen also ganz ähnliche Prinzipien der Bauweise zur Anwendung. Angesichts der zuhauf im Siedlungsgelände von Ridala verteilten Kalksteinplatten erscheint es wahrscheinlich, dass zumindest ein Teil der Wallkonstruktion mit diesen aufgefüllt bzw. gemauert wurde. Der intensiver mit Steinen verfüllte Randbereich von Ridala B wird ebenfalls mit dem Palisadenbau in Verbindung gebracht. Seine zum Zeitpunkt der Ausgrabung vorgefundene Lage indes spricht vielmehr für eine (sekundäre?) Terrassierung des stufenartig abfallenden Geländes. Eine vergleichbare Verwendung von Steinmaterialien kennen wir aus der lettischen Siedlung Vīnakalns, wo man den Abhang mit größeren Steinen und einer aufliegenden Decke von Geröll und Lehm begradigte (Graudonis 1989, 58, Abb. 35, 38). Der die gesamte Siedlung umgebende Steinstreifen ist ca. $5 \mathrm{~m}$ breit. In Ridala kann an dieser Stelle beobachtet werden, dass eben jener, gepflasterte' Abschnitt mit Siedlungsfunden, vornehmlich mit Keramik, regelrecht aufgefüllt war (siehe Kap. 8.7.2). 


\subsubsection{Wohnbauten}

Ein wesentliches, noch zu klärendes Problem ist das Verhältnis der Wohnbauten zu den Palisadenringen. Lang $(2007 b, 64)$ vermutete, es könnten zwei verschiedene Etappen der Befestigung vorliegen. Tatsächlich spricht einiges für verschiedene Bau- und Belegungsabschnitte.

Reste von Hausbauten wurden in beiden Grabungsarealen festgestellt. In Ridala B wurden diese zunächst durch Herdstellen und einige Pfostengruben identifiziert. Deren Verteilung im gegrabenen Areal schien jedoch räumlich keine Rücksicht auf die Lage der mutmaßlichen Palisaden zu nehmen, musste folglich zumindest teilweise jünger als jene datieren. Lõugas wies auf den merkwürdigen Umstand hin, dass sich einige Feuerstellen und Pfosten im unmittelbaren Umfassungsbereich direkt am abfallenden Terrain befanden. Dies könnte vorläufig, eingedenk des nur geringfügig untersuchten Bereichs, als Hinweis auf eine Belegungsphase vor der Befestigung der Plateaugrenze zu deuten sein (Lõugas 1970a, 353). In diesem Sinne hat Lõugas auch die auffällige Häufung von Steinmaterial im südöstlichen Teil von Ridala B angesprochen und somit die Idee einer Mehrphasigkeit für Ridala formuliert.

Die fraglichen Wohnbauten wurden von Lõugas und Lang näher beschrieben. Beide haben sich vornehmlich auf die bei Moora (1967) abgebildeten Grabungspläne bezogen. Je ein Hausbau konnte in Ridala A und B im Bereich innerhalb der beiden Palisadenringe ausgemacht werden. Größe, Ausrichtung und Gestalt der Bauten variieren.

In Ridala A lässt sich die Grobstruktur des mutmaßlichen Hauses bereits an der dichten Lege der Kalksteinplatten ablesen. Offenkundig hat man hier einen Hausfußboden wie in Asva F (jüngere Phase II) gepflastert (Lõugas 1970a, 351). Wandverlauf und Ecken sind deutlich im Planum sichtbar, da sich die größeren Steine (auch Feldsteine) in klaren Fluchten vom übrigen, unregelmäßig verteilten Geröll abheben. Die Gestalt eines SW-NO ausgerichteten Steinfußbodens wurde bereits vom Ausgräber beobachtet, einschließlich der Wandkanten und Ecken (Vassar 1962, 6 ff.). Die Lage des rechteckigen, 3,5-5 m breiten Wohnbaus parallel zu den Pfostenreihen des inneren Palisadenrings und eine Rechteckform lassen sich daraus deutlich ablesen (Lõugas 1970a, 351; Lang 2007b, 64). Unmittelbar südwestlich davon schließt sich ein Grubenkomplex mit Hinweisen auf dort stattgefundene Bronzegussaktivität an (siehe Kap. 7.4.1.4). Die Längenmaße des Hauses lassen sich schwer ermitteln, da ein Teil dessen jenseits der Grabungsgrenze liegt und nicht gegraben wurde. Eine der mutmaßlichen Längsseiten des Hauses ist anhand der steinfreien, ca. meterbreiten Zone zu erkennen, sie verläuft in Richtung SW-NO und wurde von Vassar bereits als solche angesprochen (Vassar 1962, 13 ff.). Die Nordseite des Hauses kann entweder im Bereich der Quadranten $3 / \mathrm{m}-1 / \mathrm{k}$ oder bei $1 / \mathrm{o}$ verlaufen, so dass seine Länge ca. $7 \mathrm{bzw} .9 \mathrm{~m}$ betrüge. Wie aus dem Planum hervorgeht, handelt es sich bei der Form der Steinpflasterung nur andeutungsweise um ein Rechteck. Einige der Steinplatten sind unregelmäßig gelagert und vermutlich sekundär verschoben und verteilt worden. 


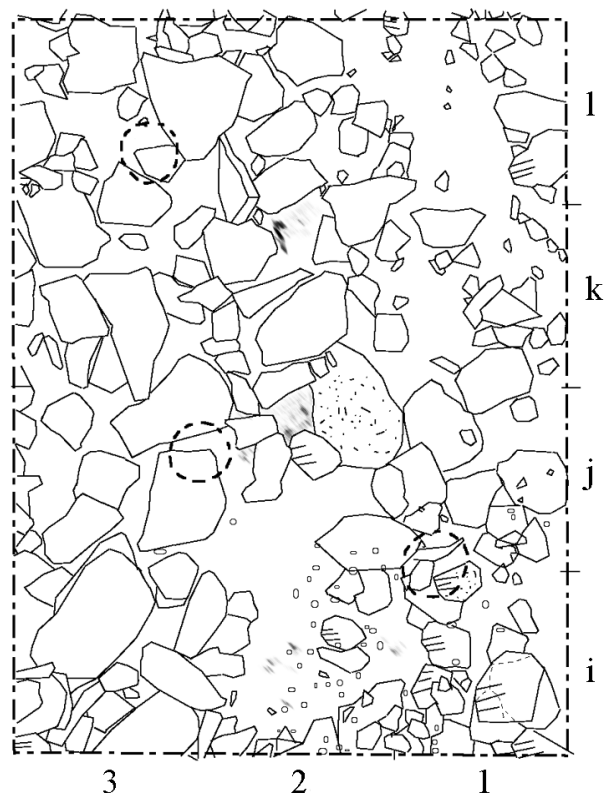

Abb. 21. Detail vom Grabungsplan Ridala A mit Lage der Pfostengruben (gestrichelte Kreise) unter dem Steinplattenniveau (nach Vassar 1962, Pl. 5 und 6 , Tiefen 80 und $100 \mathrm{~cm}$ ).
$\mathrm{Zu}$ den besagten Pfostenreihen und deren Anordnung ist festzustellen, dass die Steinpflasterung in ihrer gesamten Ausrichtung keinerlei Rücksicht auf diese zu nehmen scheint. Vielmehr kreuzt der innere Palisadenring die Steinlege nicht nur, sondern unterläuft sie geradezu. Im nördlichen Teil der Pflasterung sind fünf Pfostengruben von Steinen bedeckt (Abb. 16). Es hat demnach den Anschein, dass der Hausboden die einstige Pfostenwand überlagerte, also in keinem architektonischen Zusammenhang mit dieser steht. Dieser beachtenswerte Umstand ist in der bisherigen Beschreibung der Befunde untergegangen, obwohl dieser bereits vom Ausgräber beobachtet wurde und sich auch in den Planumzeichnungen dokumentiert findet (Abb. 21). Vassar $(1962,14,23)$ hat in seinem Grabungstagebuch auf diesen Umstand an verschiedenen Stellen hingewiesen, ohne aber diesen Punkt weiter auszuführen oder zu deuten. Dass der Wohnbau und die besagte Doppelpfostenkonstruktion sehr wahrscheinlich nicht gleichzeitig sind, geht auch aus der örtlichen Verteilung einer ganz speziellen Kategorie von Massenfunden in Siedlungskontexten, der Keramik, hervor (siehe Kap. 8.7.2). Die Gefäßreste nämlich haben ihren mengen- und gewichtsmäßigen Schwerpunkt in Bereichen des Palisadenverlaufs.

Ein weiterer Wohnbau, ein rechteckiges Langhaus ohne Steinboden, wird in Ridala B vermutet. Zunächst ist man auf diesen durch einige Herd- und Feuerstellen im Innern der Palisadenringe aufmerksam geworden. Der Ausgräber Vassar hat diese zwar beschrieben, jedoch nichts von der Existenz eines Hauses verlauten lassen. Erst Lõugas mutmaßte einen solchen Bau wegen einiger verstreuter Pfostengruben im Bereich zwischen den Palisaden. Hinweise auf Wandreste fehlen, vermutlich wurde er von den Palisadenwänden begrenzt. Außerdem sollen die zwei Herdstellen zum inneren Wohnbereich gehören (so auch Lang 2007b, 64 f.). Es sind ca. 13 unregelmäßig in der Fläche verteilte Pfostengruben, die dem Bau zugeschrieben werden, weil sie offenkundig in keiner Beziehung mit den Pfostenpaaren der Palisade stehen. Einige Gruben im Zentrum der Fläche, dort wo sich eine rechteckige Herdstelle befindet, scheinen eine Flucht anzudeuten. Sie wurden darum als dachtragende Stützen gedeutet (Lõugas 1970a, 353 f.; Lang 2007b, 64). Es solle sich demnach um einen zweischiffigen Bau 
handeln, dessen Breite auf 6-7 m und dessen Länge auf mindestens $9 \mathrm{~m}$ geschätzt werden. Ausgegangen wird also von einer Ausrichtung des Hauses parallel zur äußeren Palisade, was auf eine Gleichzeitigkeit von Befestigung und Innenbebauung schließen ließe. Wie bereits angedeutet, lassen sich jedoch keine klaren Wandverläufe erkennen, zumindest nicht anhand der Pfostengruben, die sich doch eindeutig den Mauerzügen zuordnen lassen. Es muss also offenbleiben, um was für eine Art von Wohnbau es sich hierbei handeln könnte. Denkbar wäre auch eine Art überdachter Unterbau an der Innenwand der Palisade.

\subsubsection{Brandreste}

Spuren der Brandeinwirkung, die nicht unmittelbar mit Herd- oder Feuerstellen in Verbindung zu bringen sind, hat man in beiden Grabungsteilen vielerorts feststellen können. Bislang ist man davon ausgegangen, dass in Ridala ein mehr oder weniger großflächiger Brand gewütet habe, der auch das Ende der Siedlung herbeiführte. Schließlich sei sogar anzunehmen, dass der Siedlungsbrand aus einem Kampfe oder Angriff um bzw. auf Ridala resultiert haben könne (siehe Sperling \& Luik 2010).

Bei der Sichtung der Grabungsberichte zeigt sich aber, dass die Befundlage nicht dem Bild vom Katastrophenszenario entspricht. Zunächst liegen keine Zerstörungsschichten von niedergebrannten Palisaden oder Mauern vor. In Ridala B, dort, wo sich die doppelte Ringstruktur der Palisaden anhand der Pfostengruben am deutlichsten zeigt, sind laut Grabungsbericht und Zeichenplänen nahezu keine Brandspuren festgestellt worden (siehe Abb. 20). Davon sind natürlich die Herdstellen ausgenommen. Hier zeigt sich besonders, dass die Pfostenwände entweder aus freien Stücken entfernt wurden oder zum Teil spurlos im Boden vergangen sind, zumal sich wiederholt Funde und Steine in den Gruben anhäuften, was sich sonst nicht ohne weiteres erklären ließe (so auch Vassar 1963, 19). Nur für eine einzige Pfostengrube mit partieller Steinumrandung konnte eine starke Feuereinwirkung bezeugt werden (4/p), ein Befund, den der Ausgräber zunächst noch als Feuerstelle deutete, später aber als Pfostenrest, der niedergebrannt sei (ebd., 14, 18, Pl. 5). Obwohl es sich bei dem mutmaßlichen Pfostenrest erwiesenermaßen um eine Einzelerscheinung handelt, wurde an dieser Stelle die Meinung vertreten, die Palisadenwände könnten abgebrannt sein (ebd., 18).

In Ridala A wurden Brandschichten an mehreren Stellen beobachtet, was vom Ausgräber entweder als Überreste des dortigen Hauses (mit Steinpflasterung) gedeutet wurde oder zum Befund gerechnet, den wir mittlerweile als zum selbigen Haus zugehörigen Gießerplatz kennen. Von zusammengestützten und verkohlten Palisadenwänden ist an keiner Stelle die Rede. Anders verhält es sich bei den an bestimmten Stellen aufgetretenen, linear verlaufenden Asche- und Holzkohlekonzentrationen, die teils auch als Rußschichten beschrieben werden. Diese sind verstärkt an den Seiten der rechteckigen Bodenpflasterung bemerkt und auch explizit als Reste der niedergebrannten Holzwände angesprochen worden (Vassar 1962, 6 f., 11, 16 f., 22, 27). An manchen Stellen wurden sogar noch verkohlte 
Holzreste (,Balken') erkannt, jedoch ohne diese näher zu beschreiben oder als solche in den Plänen hervorzuheben. Wie bereits festgestellt, sind die paarigen Pfostengruben der Palisaden nicht zum Hausbau gehörig und auch nicht von Hitze oder Feuer beeinträchtigt gewesen. Es lässt sich also kein Zerstörungshorizont in Verbindung mit dem Palisadenbau nachweisen.

\subsubsection{Herdstellen}

Hinweise auf mindestens eine Feuerstelle gibt es zunächst aus Ridala A. Im Ostprofil ist am nördlichsten Quadranten (1/p) eine etwa meterbreite, schwärzliche Brandschicht zu sehen, die zum größten Teil weg gegraben und nicht weiter dokumentiert wurde. Sie liegt eindeutig auf der Höhe der ebenfalls im Profil gut sichtbaren Steinpflasterung des Hausbodens, dem Siedlungsabschnitt nach den mutmaßlichen Palisadenbauten. Auf dieser knappen Grundlage ist nicht festzustellen, ob es sich tatsächlich um eine ehemalige zum Haus gehörige Feuerstelle handelt oder um eine anderweitige Brandstelle (Wandreste). Noch größer sind diesbezügliche Zweifel bei einer anderen im Bericht mehrfach genannten ,Feuerstelle' im Bereich $2 / \mathrm{j}-\mathrm{k}$, die wegen ihrer unregelmäßigen Form und Ausbreitung wohl eher als Brandherd bzw. Reste des gebrannten Hauses zu werten sind. Das erscheint aus dem Grunde wahrscheinlich, da die Steinpflasterung selbst keine bauliche Herrichtung für eine Feuerstelle (Steinumrandung etc.) erkennen lässt. Nur eine größere, darunter liegende Steinplatte zeigt deutliche Spuren der Hitzeeinwirkung (siehe Vassar 1962, 10, P1. 2-4).

Eindeutiger als Herdstellen identifizierbare Befunde konnten für Ridala B beobachtet werden. Zwei solche liegen im Innenbereich der Palisadenringe und sind offenkundig gleichzeitig in Benutzung gewesen. Der Abstand zwischen den Herdstellen beträgt etwa sechs Meter, sie sind wahrscheinlich verschiedenen Wohn- oder Arbeitsbereichen zuzuordnen. Die im nordöstlichen Teil befindliche Stelle ist streng N-S ausgerichtet und in der Form längsoval (Abb. 19). Die maximale Länge und Breite beträgt 1,5 bzw. 0,7 m. Teile der steinernen Begrenzung, die vermutlich den gesamten Bereich umfasste, sind erhalten. In der Nordostecke wurden Granitsteine verbaut, die starke Brandspuren gezeigt haben sollen (Vassar 1963, 25, 30, P1. 5). Im Südwestbereich ist gehäuft Holzkohle vorgekommen, auch Knochenstücke vom Schlachtabfall wurden vermerkt. Das Fragment einer knöchernen Pfeilspitze war auch darunter. Im Nordostteil sind einige Gussformenreste (Nr. 730) aufgetreten. Die maximale Tiefe der Herdoder Feuerstelle betrug $21 \mathrm{~cm}$ im Südbereich, $15 \mathrm{~cm}$ im nördlichen Teil. Es soll sich aber um keine sehr ausgeprägte Ascheschicht gehandelt haben (ebd., 25).

Die andere, zweite Feuerstelle befindet sich im Zentrum der Grabungsfläche von Ridala B (Abb. 22). Sie ist rundlich, misst ca. einen Meter im Durchmesser und zeichnet sich wie die letztgenannte durch einen stark von Branderde und Holzkohlepartikeln durchsetzten Kernbereich aus. Reste einer ehemaligen Umrandung lassen sich nur aus den verstreut umher liegenden Steinen erahnen. Besondere Funde sind keine gemacht worden. 
5

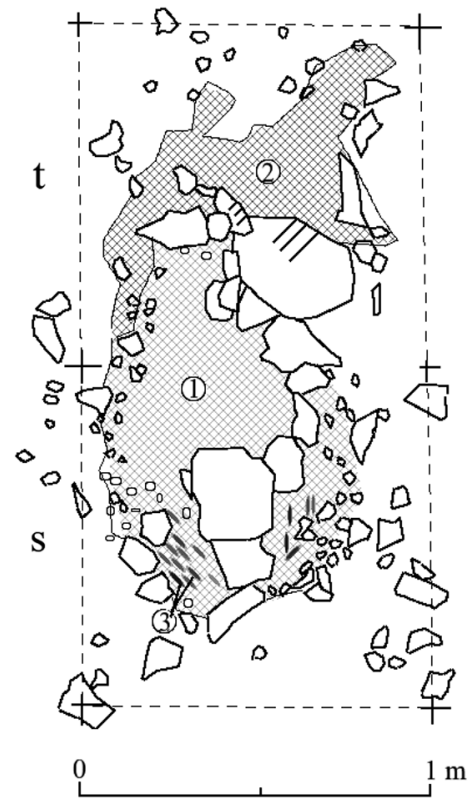

5

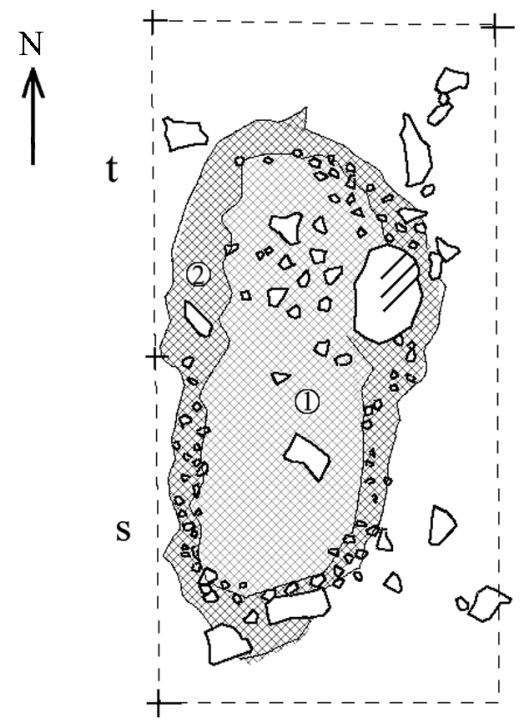

Abb. 22. Herdstelle in Quadranten 5/s-t im Planum (100 cm Tiefe) von Ridala B, vor und nach dem Entfernen der oberen Steine (nach Vassar 1963, Pl. 5). 1 Aschehaltige Erde, 2 Dunkle Erde mit Brandspuren, 3 Holzkohlereste.

Lõugas schließlich (1970a, 353) hat weitere Feuerstellen erwähnt, die sich außerhalb der eigentlichen Palisadenwände im Bereich des Abhangs am Südostrand von Ridala B befänden. Sie seien vermutlich Hinweis auf eine frühere Besiedlungsphase (vor den Palisaden). In Vassars Grabungsnotizen (1963, 11 f.) indes findet sich nur eine einzige Erwähnung für den Bereich 5-6/i: Eine mutmaßliche Feuerstelle, die nebst Keramik auch Reste von Holzkohle, Fischgräten und Knochen - also offenkundig Speise- und Schlachtabfall - enthielt. Bemerkt wurde ist diese erst, als man am Außenhang ein weiteres Planum (Tiefe 140) angelegt hatte, während der übrige, innere Bereich (bis Tiefe $120 \mathrm{~cm}$ ) bereits abgetragen und dokumentiert wurde (Abb. 23). Vassar (1963, 11 f.) äußerte an dieser Stelle den Verdacht, dass es sich eventuell um die älteste Besiedlungsspur entweder vor oder während der Palisadenerrichtung handelte. In den Plänen allerdings ist kein eindeutig als Feuerstelle o. ä. zu deutender Befund für diese Quadranten eingetragen. Es ist also nicht nachvollziehbar, was Vassar gemeint haben könnte. Spuren intensiver Feuereinwirkung finden sich dagegen im Bereich 7-8/g, im Grabungsplan Nr. 11 (ab Tiefe $140 \mathrm{~cm}$ ). Doch handelt es sich nur um einen Brandflecken mit Holzkohlepartikeln (ca. $20 \mathrm{~cm}$ im Durchmesser), der auch gut als Pfostenrest gedeutet werden könnte (so auch bei Moora 1967, Abb. 3). 


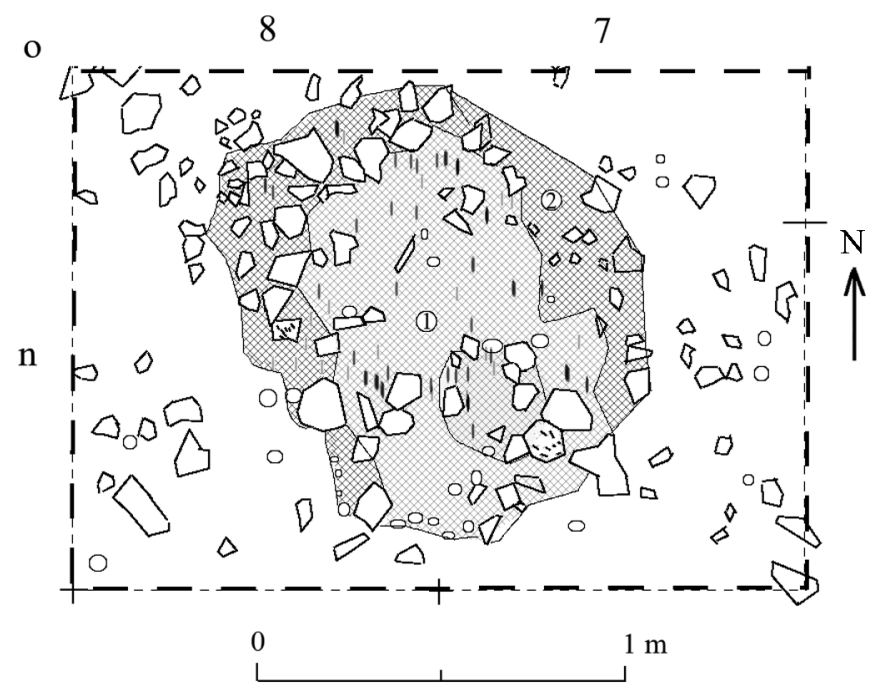

Abb. 23. Herdstelle in Quadranten 8-7/n im Planum (100 cm Tiefe) von Ridala B (nach Vassar 1963, Pl. 5). 1 Aschehaltige Erde mit Holzkohleresten, 2 Dunkle Erde mit Brandspuren.

\subsubsection{Siedlungsabfolge - Palisaden und Wohnbauten}

Lõugas vermutete in den Feuerstellen im Außenbereich der Palisadenwände Reste von Vorgängerbauten der Palisadensiedlung (Lõugas 1970a, 353). Diese Erklärung resultiert aus der Vorstellung, dass die Palisadenbauten zu einem nicht näher definierbaren Zeitpunkt zerstört wurden und danach angeblich keine Wiederbesiedlung stattfand. Die Beobachtungen zu Ridala A indes deuten auf eine umgekehrte Besiedlungsabfolge, nämlich auf eine Bebauung der einstigen Palisadenfläche, was auch aus den Grabungsberichten hervorgeht (Abb. 16). Auch machte Vassar im Zuge der Arbeiten in Ridala B die Feststellung (Vassar 1963, $18 \mathrm{f}$.), dass die Pfosten der Befestigung die Erstbesiedlung des Moränenhügels anzeigen. Zudem seien Pfostengruben mit Steinen und Keramik verfüllt worden als, so vermutete er, die Holzpfosten herausgezogen wurden (ebd., 19).

In Ridala A wurde der Palisadenbau von einem Hausbau mit Bodenpflasterung und dem südlich angelegten Bronzeverarbeitungsplatz überlagert. Es fehlt der räumliche Bezug zwischen Palisaden und Wohnbau. Brandreste stehen hier eindeutig mit Letzterem in Zusammenhang. Ein Zerstörungshorizont, vom Brand der Palisaden, gibt sich nicht zu erkennen. Auch mangelt es an überzeugenden Hinweisen auf einen erfolgten Gewaltakt von außen (Sperling \& Luik 2010). Es erscheint wahrscheinlich, dass auch im Ostteil B eine Siedlungsabfolge stattfand, in deren Verlauf die Palisaden errichtet und relativ kurze Zeit später wieder entfernt wurden, das Areal aber weiterhin bebaut und besiedelt wurde. Auch hat die hiesige Fundverteilung diese Annahme bestätigen können. Bei der Keramik ist aufgefallen, dass diese sich schwerpunktmäßig auf die Steinpflasterung verteilt, die sich ihrerseits 
als Überrest einer Terrassenfestigung überzeugend deuten lässt. Der gesamte Außenbereich, einschließlich der einstigen Palisade, ist also erst im Nachhinein besiedelt und bebaut worden.

Auch spricht nichts gegen die Gleichzeitigkeit der beiden Palisadenringe, wenn dies auch mangels zureichender Dokumentationsmethoden und der ausschnitthaft gegrabenen Fläche nicht vollends geklärt werden kann (ca. ein Zehntel der Siedlung untersucht). V. Lang hält es für wahrscheinlich, dass die Palisadenringe von Ridala nicht gleichzeitig entstanden sind, verweist aber auf einen möglichen ideellen Zusammenhang mit späteren, eisenzeitlichen Burgwällen mit zweifachen Umfassungsringen auf Saaremaa (2007b, 64 f., 77, Abb. 32).

Die Datierung der Keramik, Gussformen und Bronzen (Tüllenbeil) aus Ridala legt einen Belegungszeitraum der Siedlung innerhalb der Montelius-Periode VI nahe (750-550 BC), d. h. inklusive Bau und Abbruch der Palisadenringe sowie der Hausbauten. Dem oben Dargelegten zufolge hat es den Anschein, dass die Zeit der Palisadennutzung vergleichsweise kurz gewesen sein müsste, denn das meiste Siedlungsmaterial lässt sich vornehmlich dem jüngeren Siedlungshorizont zuordnen. Dies wirft indes auch ein wenig Licht auf den Charakter dieser besonderen Bauten, der nicht notwendigerweise als rein fortifikatorisch angesehen werden muss. Auf andere, prominentere Palisadenbauten der Spätbronze- und Früheisenzeit wie Vistad (Östergotland) und Havor (Gotland) jenseits der Ostsee wurde in diesem Zusammenhang bereits hingewiesen (Sperling \& Luik 2010). In beiden Plätzen finden sich nur äußerst wenige materielle Besiedlungsspuren. In Vistad trägt die Keramik ortsfremde Züge, Stilmerkmale des sog. Lausitzer Urnenfelderkreises (mutmaßlich ostdeutsch-polnischer Provenienz), was die Idee saisonaler Besuche von Menschengruppen aus dem Bereich des südlichen Ostseegebiets aufbrachte. Frühe Eisengewinnung und -verarbeitung vor Ort sollen zu dieser besonderen Mittelpunktrolle und Anziehung des Platzes beigetragen haben. Die Palisadenzüge hätten nach Ansicht der Ausgräber wohl mehr eine symbolische Bedeutung gehabt, um die exklusiven Aktivitäten im Innenbereich der Siedlung von der Außenwelt abzuschirmen (Larsson \& Hulthén 2004, 52). Militärische oder fortifikatorische Beweggründe in der Errichtung solcher und ähnlicher Palisadenanlagen der Bronzezeit sind nicht unbedingt zwingend anzunehmen oder vorauszusetzen. Die Errichtung solcher Bauten an Siedlungsplätzen in markanten Landschaftspunkten hatte neben der offensichtlichen Funktion, Annäherungshindernis zu sein, auch einen psychologischen Aspekt und eine Symbolbedeutung in Verbindung mit Macht- und Mittelpunktdemonstration der ansässigen Bevölkerung (oder auch gesellschaftlichen Elite) (so auch Vasks 2007, 36 f.). Die Nutzung von Kreispalisaden oder umzäunten Plätzen kann administrativ-politischer, wirtschaftlicher und/oder religiös-kultischer Art zugleich gewesen sein. Für Ridala verlangt es nach gründlicheren und umfassenderen Untersuchung der Palisadenkonstruktion, um in der weiteren Funktionsdeutung der Siedlung (sbegrenzung) eine größere und verlässlichere Diskussions- und Argumentationsbasis zu gewinnen. Bei dem derzeitigen Untersuchungsstand und dem Wissen um Kreisgraben- und Palisadenanlagen des Jüngeren- und Spätneolithikums sowie den Befestigungsbauten 
der Bronzezeit in Mitteleuropa (Meyer \& Raetzel-Fabian 2006; Primas 2008, 41 ff.) bleiben für Ridala viele Erklärungsmöglichkeiten: von befestigter Siedlung, über Fluchtburg und Viehpferch bis zum Versammlungs- und Ritualplatz mit besonderen Baumerkmalen und -maßen (astronomische Bezüge?).

\subsection{Kaali}

Der Kraterplatz zählt mittlerweile zu den geologischen und archäologischen Hauptattraktionen der Insel Saaremaa und ist seit jeher ein touristischer Anziehungspunkt (Abb. 24). Bekannt ist der Krater auch als „Opferplatz“ oder „Sakralort“, obwohl er archäologisch noch unzureichend erforscht ist. Um ihn ranken sich diverse in der Folklore überlieferte Legenden, die mit seiner ,himmlischen Entstehung oder etwa den Geheimnissen um den Kratersee in Zusammenhang gebracht werden (Abb. 24; dazu Lang 2007b, 76 f.). Seit den Ausgrabungen der 1970er Jahre wird Kaali der Öffentlichkeit als eine Bronzezeitfestung und ein eisenzeitlicher Kultplatz präsentiert (zuletzt Kraut 2004), und es hat den Anschein, als hätte die Arbeit der Archäologen den Mythen und Legenden um diesen Platz ihren langersehnten authentischen Kern verschafft. Der KaaliAusgräber Vello Lõugas (1996) hat dies in seinem populärwissenschaftlichen Buch Kaali kraatriväljal Phaethonit otsimas (dt. „Suche nach Phaethon im Kraterfeld von Kaali“) zumindest so aussehen lassen. Dennoch kamen im Zuge der Ausgrabungen bemerkenswerte Befundstrukturen und Ergebnisse zutage:

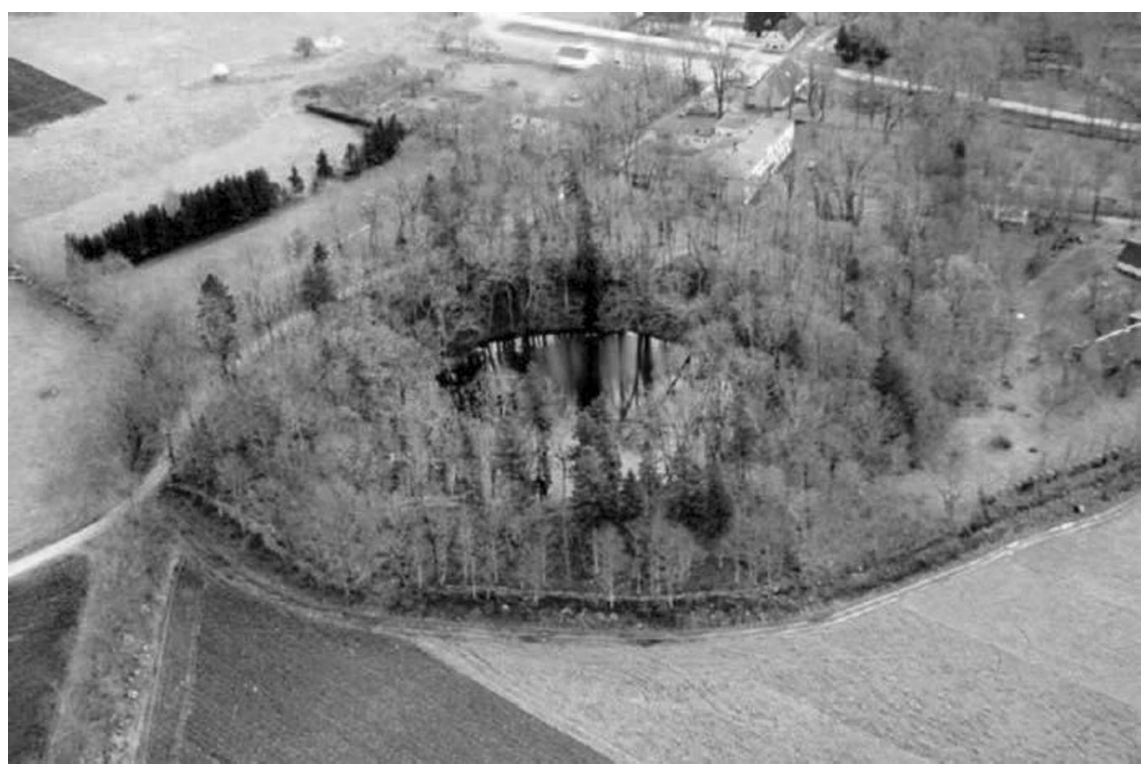

Abb. 24. Der Meteoritenkrater von Kaali (Luftfoto von Ants Kraut, National Heritage Board of Estonia). 
so etwa die Reste einer Trockenmauer, Spuren spätbronzezeitlicher Besiedlung mit Fundmaterial von gewisser Exklusivität (u. a. Belege für Metallguss, auch Feinkeramik), mindestens ein Hortfund mit Silberobjekten, und an anderen Stellen Tierknochen, die gern als Schlachtopfer interpretiert werden. Allerdings ist die Dokumentation der Ausgrabungsarbeiten entweder sehr mangelhaft durchgeführt worden oder es sind wichtigste Erläuterungen und Beschreibungen relevanter Befund- und Kontextsituationen nicht überliefert (bzw. im Archiv nicht auffindbar). Bei genauerer Prüfung des Daten- und Fundmaterials von Kaali zeigt sich, dass die verfügbare Fakten- und Indizienlage nicht immer sehr verlässlich oder sicher ist und der Forschungsstand zur Archäologie des Fundplatzes nach wie vor unzureichend. Zwar sollen solche bedeutungsschweren kategorischen Bezeichnungen wie „Kultplatz“, „Opferstätte“ und „Befestigung“ auf die symbolische Bedeutung und Funktion des Meteoritenkraters in der Vergangenheit aufmerksam machen, doch sind die bislang verwertbaren Indizien und Details der bisherigen archäologischen Forschung entweder zu dürftig oder widersprüchlich, um in Fragen zur Besiedlungsgeschichte und Funktion des Platzes endgültige Klarheit zu bekommen.

\subsubsection{Der Meteoritenkrater}

Kaali, fast zentral auf der Insel Saaremaa gelegen, kann zu den bestuntersuchtesten der ca. 170 auf der Welt bekannten Krater gezählt werden, zumindest was dessen Geologie und Geomorphologie betrifft (Veski et al. 2004, 197). Der KaaliHauptkrater ist mit 105-110 m im Durchmesser und 16-22 m Tiefe der größte in einem Feld von neun Kratern, alle zwischen 12 und $40 \mathrm{~m}$ im Durchmesser, verteilt auf einer Fläche von $1 \mathrm{~km}^{2}$ (Raukas \& Stankowski 2010, 64). Man geht davon aus, dass ein mindestens 450 Tonnen schwerer und ca. 4,8 m großer Meteorit mit $21 \mathrm{~km} / \mathrm{s}$ Einschlagsgeschwindigkeit für die Bildung des Kraters verantwortlich war. Die für die Formung eines derart großen Kraters benötigte Energiefreisetzung soll bei vorsichtiger Schätzung auf eine Schlagkraft von mindestens 1-2 Kilotonnen TNT zurückgehen (Veski et al. 2007, 267 f.; Raukas \& Stankowski 2010, 63).

Der Kratersee misst je nach Stand zwischen 30 und $60 \mathrm{~m}$ in der Breite, dessen Spiegel fällt je nach Jahreszeit, Niederschlägen und Grundwasserstand unterschiedlich hoch aus, beträgt die meiste Zeit aber nur wenige Meter $(0,5-4 \mathrm{~m})$. Im Spätsommer oder Frühherbst kann dieser sogar fast austrocknen (Abb. 25). Aus diversen Bohrungen im Krater geht hervor, dass das Becken mit 5-6 m dicken See- und Sumpfablagerungen angefüllt ist. Unter einem $2 \mathrm{~m}$ starken, kalkhaltigen Schlammboden (Gyttja) mit vielen organischen Einschlüssen liegen einige Meter schlammig-lehmiger Schichten mit reichlich Baumhölzern und Pflanzenresten (Veski et al. 2004, 199, Tab. 1; Moora et al. 2008, 222 ff., Abb. 11).

Nicht ganz unproblematisch verliefen bislang die Versuche, über diverse Bohrungen die Geologie und Sedimentmorphologie des Kratersees zu bestimmen, da die kompakten Einlagerungen von Steinen und Baumhölzern unter den Schlammschichten entweder nicht durchdrungen werden konnten oder die Bohrkernprofile 


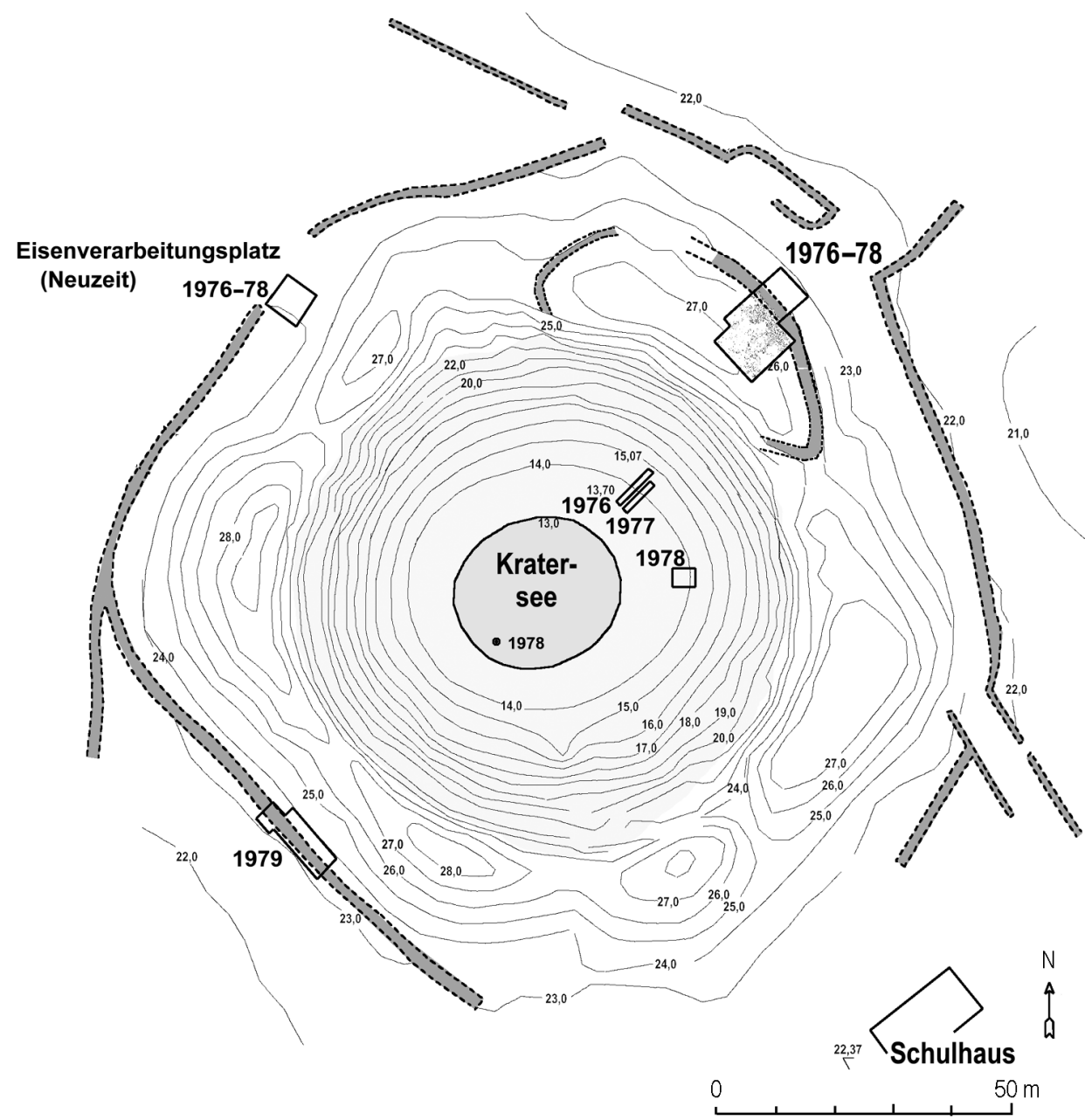

Abb. 25. Der Kratersee von Kaali, die Grabungsareale und Mauerkonturen (grau) (nach Moora et al. 2008, Abb. 1; Mägi 2013 (modifiziert; Wasserspiegelstand: Sommer 2002)).

wegen der Sedimentverlagerungen im Kratertrichter nicht korrelierten. Daran sind sowohl natürlich als auch menschlich ausgelöste Faktoren beteiligt gewesen (Hangerosion durch großen Besucherandrang, Abfälle im See etc.) (Moora et al. 2008; Raukas \& Stankowski 2010, 64). Die vielen rezenten Testbohrungen (mind. 98) und Sondagen im Kraterbereich ergeben nicht in alle Fällen ein einheitliches Bild - ein Umstand, der es nach wie vor schwierig macht, die untersten bzw. ältesten Sedimente nach der Kraterentstehung zu erfassen und diese u. a. für Datierungszwecke des Kraters (d. h. Einschlagszeit) zu nutzen. Mittlerweile kann man auf eine Fülle von chronologischen Messdaten zurückgreifen, die jedoch in der Zeitspanne sehr breit streuen. Von den Bohrproben in Bereichen der Kratermitte und des unteren Kraterrands liegen derzeit 31 Datierungen vor. 
Bis auf vier AMS-Daten (terrestrische Makrofossilien) beruft man sich auf ${ }^{14} \mathrm{C}$-Messungen, die selbst bei Beprobungen der Gyttja in tieferen Schichtenzusammenhänge $(>3,65 \mathrm{~m})$ in einem breiten Zeitintervall von 1400-200 cal. BC streuen (Veski et al. 2004, 199 f., Abb. 2 f., Tab. 3). Die im Labor der Universität Uppsala erstellten AMS-Messungen an einer Laufkäferart (Carabidae) und organischen Resten (Birkensamen, Fichten- und Kiefernadeln) aus dem Schichtensegment des Kratersees (Tiefen 4,79-4,83 m) erbrachten Daten wie 1690-1510, $1130-920$ und 1000-830 cal. BC. Ein einziges Radiokarbondatum aus einer Torfschicht im Kraterinnern (4,85 m tief) beläuft sich auf 1740-1620 cal. BC (1-sigma) (ebd., 202, Tab. 3). Es sind also nicht mehr als zwei Messwerte, die auf Vegetation des Kraterbereichs in der Älteren Bronzezeit hindeuten. Paläobotanische Untersuchungen der 1980er haben das Alter des Kraters - noch ohne Kenntnis dieser Daten - noch weitaus höher eingeschätzt (mind. 4000 BP; Raukas et al. 2005, 352). Auch wird der Bewuchs des Kratertrichters nach dem verheerenden Meteoriteneinschlag erst allmählich eingesetzt haben, da der zerborstene, silurische Dolomit zumindest eine Weile lang offen gelegen haben muss. Angesichts der breiten Streuung der Messwerte kann den aus dem Kraterbereich stammenden Radiokarbondatierungen nur noch bedingt Vertrauen geschenkt werden. Die Sedimentverlagerungen (speziell der organischen Einschlüsse) im Kratertrichter und wahrscheinliche ${ }^{14} \mathrm{C}$-Kontaminationen stellen ganz offensichtlich hinderliche Faktoren für eine verlässliche Altersbestimmung dar. ${ }^{34}$

Was die jüngste Kontroverse um das Alter des Kaali-Kraters ungemein belebte, ist die von Siim Veski et al. seit 2001 anhand von Untersuchungen an Pollenspektren entwickelte Hypothese, wonach der Meteoriteneinschlag mit Wahrscheinlichkeit während der Spätbronzezeit stattgefunden habe und Bewohner der Asva-Siedlung Zeuge bzw. gar Opfer der verheerenden Einschlags gewesen seien. Der Aufprall soll eine ökologische Katastrophe ausgelöst haben, der womöglich mit dem Brandhorizont der Siedlung Asva in Zusammenhang zu bringen sei (Veski et al. 2001; 2002). Bereits kurz nach Beginn der ersten geologisch-archäologischen Untersuchungen in Kaali im Jahre 1976, mitinitiiert von V. Lõugas, kamen erste ${ }^{14} \mathrm{C}$-Messungen zutage, die ein mutmaßliches Alter des Kraters zwischen 800 und 400 BC (unkal.) anzeigen sollten. Da die aus den Brandschichten von Asva gewonnenen ${ }^{14} \mathrm{C}$-Messungen grob in diesen Zeitraum datierten, machte die Hypothese einer vom Meteoriteneinschlag verursachten Brandkatastrophe schon damals ihre Schlagzeilen, wenn auch zunächst nur vor einem populärwissenschaftlichen Forum (Aaloe et al. 1977; Lõugas 1996). ${ }^{35}$ Von dieser Idee inspiriert, und gestützt auf gewisse archäologische Befunde, suchte eine Gruppe estnischer Paläobotaniker und Paläoökologen bestimmte Anomalien im Pollenspektrum vor dem Hintergrund

${ }^{34}$ Nichtsdestotrotz wird in der Kontroverse um das Alter von Kaali vorzugsweise mit Einzeldaten (z. B. Ua-1796: 1690-1510 cal. BC) argumentiert (z. B. Veski et al. 2007, 269).

35 Lõugas, zwischenzeitlich begeisterter Anhänger dieser Theorie einer durch den Meteoriten verursachten Bronzezeitkatastrophe auf Saaremaa (u. a. zum Niedergang von Asva führend), ist bereits längst von dieser Idee abgerückt, weil sich Hinweise auf eine Älterdatierung des Kaali-Impakts mehrten (Lõugas \& Selirand 1989, 209 f.; Lõugas 1996, 65 f.). 
einer Kaali-Katastrophe zu erklären (Veski et al. 2001; 2002). Streitthema ist eine Torfschicht des im 6 km nordwestlich von Kaali gelegenen Piila-Hochmoors. Dort gibt es einen Anreicherungshorizont des bodenfremden (extraterrestrischen?) Minerals Iridium (Ir), der im Pollenspektrum mit Anzeigern für Flächenbrände und einem Kulturpflanzenminimum korreliert (Abnahme um fast zwei Drittel). Auf diese Periode folgen Indikatoren für einen wachsenden Bestand an anspruchslosen, gewöhnlich in bodenärmeren Gebieten heimischen Kiefern. Drei Pollenzonen werden in pre-impact-, after-impact- und sog. recovery-Stufen unterteilt, bestimmt von Prämissen, wonach der Ir-Horizont von Piila den Meteoriteneinschlag in Kaali anzeige, dieser wiederum zwischen 800 und 400 cal. BC passierte (Veski et al. 2001, 1373 ff.).

Dieser Versuch, einen kosmisch ausgelösten Hiatus im bronzezeitlichen Siedlungswesen sowohl im paläobotanischen als auch im archäologischen Befund sichtbar zu machen, hat in Fachwelt und Öffentlichkeit für Aufsehen gesorgt, sich in der wissenschaftlichen Diskussion jedoch nicht lange behaupten können. ${ }^{36}$ Das Argument des erhöhten, Ir-Nachweises in den Pollendiagrammen wird nicht mehr zwingend im Zusammenhang mit einem Meteoritenkörper gesehen, vielmehr wird dies unter Verweis auf die Verbreitung und Erhöhung mineralischer Bestandteile im Boden als ein Ergebnis natürlicher Prozesse betrachtet, kann also gut möglich das Ergebnis periodisch eintretender Waldbrände sein (Raukas et al. 2005, 350 ff.). Übrigens wurden am selben Piila-Torfmoor bereits früher Versuche gemacht, den Zeitpunkt des Meteoriteneinschlags über bodenfremde Minerale zu bestimmen. Eine Torfschicht mit erhöhten Anteilen siliziumhaltiger Mikrospherule wurde bereits von Raukas et al. in 6400 cal. BC datiert (siehe Veski et al. 2004, 202). Auch wird eingeräumt, dass die in den unteren Füllsedimenten des Kaali-Kraters anzufindenden Fichtenpollen bereits ab 3800 BC in den Pollendiagrammen von Saaremaa auftreten (Veski et al. 2007, 269). Jüngst versuchte man sich in der Datierungsfrage auch an der Thermolumineszenz-Methode an Quarzkörnern aus dem Krater. Die Messwerte liegen zwischen 5800 und 5600 BP (Raukas \& Stankowski 2010, 64).

Von der Hypothese des Meteorit-Events als Auslöser einer ökologischen Katastrophe am Übergang zur Früheisenzeit ist man mittlerweile abgegangen. Allerdings sind einige Forscher, Naturwissenschaftler und Archäologen, von der Idee besonders angetan, im Meteoritenfall auf Saaremaa ein einzigartiges Naturphänomen sehen, welches sich im kulturellen Gedächtnis der vorgeschichtlichen Bewohner der Ostseeinsel und Nachbarregionen tief eingeprägt haben muss und geradezu prädestiniert sei für Legendenbildungen um den Ort und seine ,himmlische' Entstehungsgeschichte. Kaali hat bereits vor den ersten archäologischen Nachforschungen in den späten 1970ern eine große Faszination auf Kenner und

\footnotetext{
36 Auch hat man versucht, abgesehen von der nicht haltbaren Datierung, das zerstörerische Ausmaß des Meteor-Aufpralls für die Kaali-Umgebung zu relativieren. Demnach sei die in der Fachliteratur postulierte Sprengkraft des Einschlags, verglichen mit dem der Hiroshima-Atombombe (ca. 20 Kilotonnen), um ein Vielfaches zu hoch angesetzt (Raukas et al. 2003; vgl. Veski et al. 2002, 108).
} 
Besucher des Ortes ausgeübt, doch hat erst die Entdeckung vorgeschichtlicher Siedlungsreste (u. a. Steinwälle, Tierknochenfunde) und einiger preziöser Silberobjekte der Forschung und Öffentlichkeit zur Idee verholfen, in Kaali nicht nur einen Ort mit besonderer, mythischer Aura zu sehen, sondern eine einstige Kultstätte oder einen Sakralort (Veski et al. 2004; 2007; auch Lang 2007b). Dies formulierte bereits Lõugas (1996), indem er die Kratersiedlung nicht nur zum Schauplatz des von Tacitus beschriebenen Nerthus-Kults und die Insel Saaremaa zur mythischen Heimstatt der von Germanen verehrten Göttin machte, sondern im Einschlag des Meteoriten in Kaali eine Art historischen Kern im Antikenmythos vom Unfall des Phaethon (Sohn des Helios) mit seinem Sonnenwagen vermutete. Andere Forscher glauben, dass das Ereignis der Kaali-Katastrophe im finnischen Sagenepos der Kalevala tradiert sei, die Entstehung des Mythos der klassischen Antike um den Himmelsstürmer Phaethon womöglich gar von dem nämlichen Meteoriteneinfall im Ostbaltikum beeinflusst gewesen sei (Haas et al. 2003, 61 f.; kritisch dazu Mägi 2003).

Bemerkenswerterweise kommen Kritik und Widerspruch nicht vom archäologischen Fach, sondern vonseiten eines kleinen Geologen- und Paläoökologenkreises der sich mit der gesamten Faktenlage um Kaali eingehender auseinandersetzte und der Sakralplatztheorie nüchterner und weniger emotional gegenübersteht (Raukas et al. 2003; Moora et al. 2008, 209 f.). Der Fundplatz Kaali bietet also Potential für kontroverse Diskussionen um dessen soziopolitische und sakrale Mittelpunktfunktion in der Vorgeschichte der Insel Saaremaa. Problematisch bestellt bleibt es aber um die Informationslage zu den bronzezeitlichen (und jüngeren) Spuren der Besiedlung und der Nutzung des Platzes als mutmaßlichen Sakraloder Ritualort. In punkto Aufnahme und Aufarbeitung ist die archäologische Befundsituation in Kaali durchaus mit dem schlechten Dokumentationsstand der Grabungskampagnen der Palisadensiedlung von Ridala vergleichbar. Angesichts der in der archäologischen Literatur verbreiteten Hypothesen zur Sakralfunktion (eisenzeitlicher Opferplatz) und zum Befestigungscharakter (Befestigung aus der Bronzezeit; Kraut 2004) der Kratersiedlung ist diese Forschungssituation umso bedauerlicher.

\subsubsection{Die Kratersiedlung und die archäologische Befundsituation}

Es sei vorneweg genommen, dass sich in der Beschreibung der Grabungsbefunde nur auf die drei in Artikelform verfassten Vorberichte zugreifen lässt (Lõugas 1978a; 1978b; 1980). Ein offizieller Report mit einer detaillierten Dokumentation der archäologischen Arbeiten in Kaali liegt nicht vor, er ist vermutlich auch nicht angefertigt worden (mdl. Mitteilung Mirja Ots, Archiv des AI in Tallinn). Nur zwei Grabungspläne (Abb. 26) sind vorhanden, dazu ein Fundkartierungsplan, weitere Zeichnungen (von Profilen u. a.) indes fehlen. Im Vorfeld geplanter denkmalpflegerischer Instandsetzung und Baumaßnahmen hat Marika Mägi kürzlich eine Evaluierung und Revision des unter Denkmalschutz stehenden archäologischen Bestands vorgenommen. Dabei erfolgte auch eine kritische Prüfung und Diskussion 


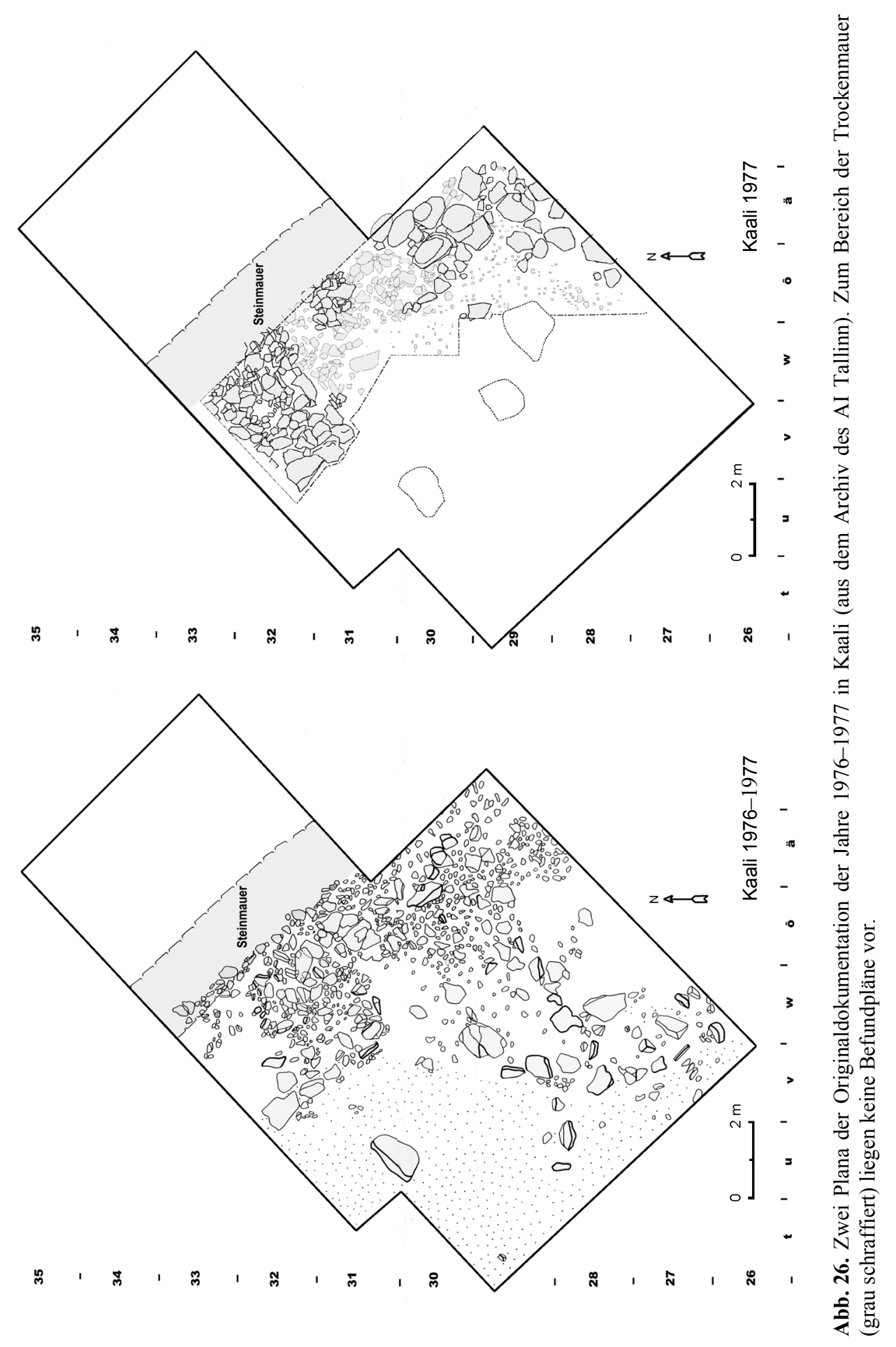


der bisherigen Untersuchungsergebnisse, auch in Bezug auf die gemäß der derzeitigen Faktenlage nicht sachgerechte Titulierung der Kratersiedlung als „befestigt“ bzw. als „Opferplatz“ (Mägi 2013). ${ }^{37}$

Die Ausgrabungen in Kaali in den Jahren 1976-1979 konzentrierten sich im Wesentlichen auf folgende Stellen (Abb. 25):

- den Randbereich des Kratersees (Sondierungsschnitte) ${ }^{38}$

- den NO-Bereich des Kraterwalls

- den äußeren Steinmauerring und den anliegenden Eisenverarbeitungsplatz (neuzeitlich).

In der ersten Grabungskampagne (1976) wurde ein Schnitt in SW-NO Richtung durch das Kraterplateau angelegt, in der Folge wurde an dieser Stelle eine Fläche von $135 \mathrm{~m}^{2}$ untersucht. Gleich zu Grabungsbeginn kamen in diesem Bereich des Kraterwalls die bislang spektakulärsten Funde zutage: Zwei Spiralarmringe und ein Halsring aus Silberblech sind mutmaßliche Bestandteile eines Hortkomplexes, ein weiterer silberner Spiralfingerring wurde separat gefunden (Lõugas 1996, 59 ff.). Genauere Angaben zu den Auffindungsumständen, zu den stratigraphischen Kontexten (Lage, Positionierung der Stücke, Fundtiefe), fehlen. Die Funde sollen aber im Zusammenhang mit einer im Wallbereich erfassten Kulturschicht gemacht worden sein. Die Silberfunde, gemeinhin als Votivniederlegungen gedeutet, stammen vermutlich aus der Späten Römischen Eisenzeit (3.-5. Jahrhundert u. Z.) (Lõugas 1996, 61; Lang 2007b, 77; Tamla \& Kiudsoo 2009, 16 f.), sind somit offenkundig jüngeren Datums als die freigelegten Steinbauten in diesem Grabungsbereich (siehe unten). Die Metallfunde von Kaali (Opfer? Weihefunde?) jedenfalls trugen, trotz der Unklarheit bezüglich der Fundumstände und des zeitlichen Verhältnisses zur Siedlungsaktivität (und Mauerkonstruktion) im Kraterbereich, wesentlich zur Anwendung der Kult- oder Sakralplatztheorie bei (z. B. Lõugas 1996, 61 f.).

Im nämlichen Bereich der Terrasse auf dem Kraterwall kamen ab einer Schichtentiefe von 30-40 cm die Reste mit Kalksteinplatten ausgelegter Baukonstruktionen zum Vorschein (Abb. 26). Mindestens ein Bau ist in der Anordnung der gepflasterten Steine rechteckig, ähnlich der Bauten mit Steinböden in Asva und Ridala. Das archäologische Fundspektrum setzt sich aus ca. 300 Gefäßscherben, Fragmenten von Gussformen und Tiegeln zusammen, sowie aus nicht näher bestimmten Fundmengen tierischen Schlachtabfalls (... and quite a number of animal

37 Unter Kaali sind im amtlichen Denkmalschutzregister gelistet: 1. ,befestigte Siedlung und Opferplatz“ (estn. kindlustatud asula ja ohverdamiskoht) (unter Nummer 12602), und 2. ein neuzeitlicher „Eisenverarbeitungsplatz“ (rauasulatuskoht) (Nr. 12603). Siehe http://register.muinas.ee/?menuID= monument\&action=view\&id=12602 (am 9.1.2014 zuletzt eingesehen). Diese Funddenkmäler sind auch vor Ort als solche ausgeschildert. Mägi $(2013,15$ f.) plädiert anstelle der bisherigen Doppelbezeichnung (unter Nr. 12602) für eine Verwendung des ihrer Meinung nach neutraleren Terminus linnus (Burgberg-Siedlung).

38 Nennenswerte Funde oder Beobachtungen hat es dort keine gegeben. Lõugas setzte bei einem seiner Versuche der archäologischen Sondierung des Kratersees im Jahre 1978 sogar einen Senkkasten ein und ließ das Wasser des Sees teilweise völlig abpumpen. Dabei konnte er wegen der kompakten Lagen großer Baumhölzer nur bis ca. zwei Meter Tiefe vordringen. Dendrodatiert wurde das Splintholz eines spätmittelalterlichen Eichenstamms (ermitteltes Datum: 1426 u. Z.; Lõugas 1996, 148 ff.). 
bones; Lõugas 1978a, 64). Als interessant erweist sich die Befundsituation auf dem terrassenförmigen Plateau in 0,8 m Tiefe, wo sich die Konturen eines 3,8 m breiten Steinbodens mit Kalksteinplatten auftaten. Bei diesem handelt es sich ganz offensichtlich um den Befund auf dem mit „Schicht IV“ bezeichneten Plan (kiht IV; Abb. 26, rechts, und Abb. 27). Die Bauten wurden aber nur teilweise erfasst und laufen jenseits der Grabungsgrenzen im NW- und SO-Bereich weiter. In der Folge wurden weitere Gefäßscherben gesammelt (1415 Stück) und insgesamt 369 Fundnummern vergeben. Zum Fundmaterial gehören die für Asva und Ridala typische Keramik grober Machart mit Besenstrich- und Grübchenverzierung und die der Schalen mit Henkeln, Oberflächenpolitur und Abrollstempeln (Taf. 55 f.). Teile der handgemachten, geglätteten Grobkeramik weisen Lõugas zufolge in die Späte Römische Eisenzeit, wegen der vemuteten Ähnlichkeiten mit Keramikfunden aus dem unweit von Kaali befindlichen tarand-Grab von Liiva-Putla (Lõugas 1996, 61 f.). Beobachtungen hinsichtlich einer Schichtenfolge oder -trennung hat es keine gegeben oder diese wurden nicht schriftlich oder zeichnerisch festgehalten. Die Dicke der Kulturschicht soll aber im Bereich des Wallaußenhangs eine Dicke von bis zu zwei Metern erreicht haben. Verwirrung stiftend ist die anderswo getätigte Aussage, die Siedlungsspuren in Verbindung mit der Steinarchitektur im Bereich des Wallplateaus seien vermutlich sämtlich spätbronzezeitlich. ${ }^{39}$

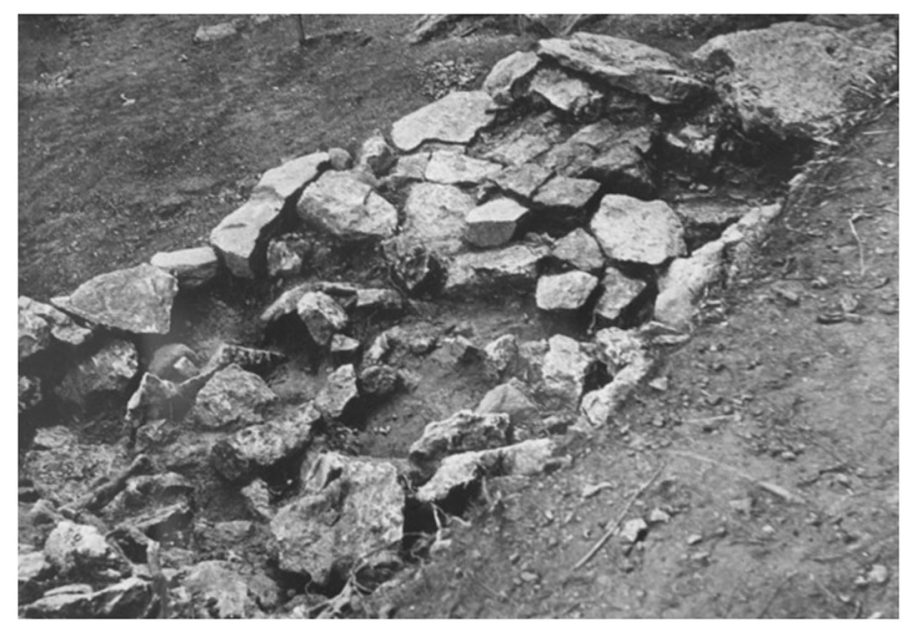

Abb. 27. Foto der 1977 freigelegten Steinstruktur (aus dem Archiv des AI). Diese kam im Mittelbereich, am nördlichen Rand des Grabungsareals zum Vorschein, angrenzend an die spätere Trockenmauer (siehe Abb. 26, rechts).

39 So in dem 1977 (oder später) von Lõugas verfassten Begleittext im Denkmalschutzregister (http://register.muinas.ee/?menuID=monument\&action=view\&id=12602 - am 9.1.2014 zuletzt eingesehen). Valter Lang merkte in diesem Zusammenhang an (per E-Mail vom 03.02.2014), dass zum tarand-Grab von Liiva-Putla auch ein Schichtenhorizont der Vorrömischen Eisenzeit gehört (siehe auch Lang 1996, 303). Kaali könnte also periodisch in der Spätbronzezeit und Vorrömischen Eisenzeit als Wohn- oder Kultplatz frequentiert worden sein - seiner Meinung nach ein weiterer Hinweis auf eine gegenüber Asva und Ridala gesonderte Funktion des Kraterplatzes. 
Aufmerksamkeit in Zusammenhang mit der Kult-, Sakral- oder Opferplatztheorie und Kaali erregte ein weiterer Befund im Bereich des Kraterplateaus: Dem Bericht des Ausgräbers zufolge stieß man bereits im Vorfeld der Grabungen in Kaali, im Zuge erster Inspektionen im Jahr 1976, auf Spuren einer soliden Trockensteinmauer. Diese trat im nämlichen Plateaubereich zutage (Lõugas 1978a, 64). Schon im Bereich der mutmaßlich spätbronzezeitlichen, mit Steinplatten planierten Häuserböden ist man mit dem Freilegen von großen Mengen einer Mauer zugehörigen Kalksteinschutts beschäftigt gewesen (herabgebröckelte Mauersteine). Weitere Untersuchungen im nordöstlichen Wallbereich ergaben eine im Halbbogen $110 \mathrm{~m}$ lange und $2 \mathrm{~m}$ dicke Kalksteinmauer, die teilweise noch eine Höhe von bis zu 2,2 m erreichte (Lõugas 1978b, 327, Taf. I: 2). Sogar von verbrannten Holzresten ist die Rede (hinter der Kalksteinmauer; ebd. 327), doch fehlt es auch hier wieder an jeglichen überprüfbaren Belegen. Somit könnte in diesem Bereich einiges auf eine Art Pfostenschlitzmauerkonstruktion deuten (Abb. 28). Da der Mauerzug die Steinplattenpflasterungen überlagerte und von einer Fortsetzung der Kulturschicht beidseits der Mauer berichtet wird, ist davon auszugehen, dass die Errichtung der Mauer zu einem viel späteren Zeitpunkt stattfand. Auch ist in Verbindung mit den mutmaßlich spätbronzezeitlichen Steinkonstruktionen von einer offenen, also unbefestigten Siedlungsphase die Rede (ebd., 329).

Im Jahre 1979 konzentrierten sich archäologische Untersuchungen auf unmittelbar an den Meteoritenkrater anschließende Bereiche, auch den neuzeitlichen Eisenverarbeitungsplatz. Insbesondere die den Krater perimetrisch umlaufende und noch heute gut sichtbare, massive Steinmauer aus Feldsteinen gab hinsichtlich Entstehungszeitpunkt und Zweck der Anlage neue Rätsel auf. Lõugas (1980, 358 f., Taf. II: 1)

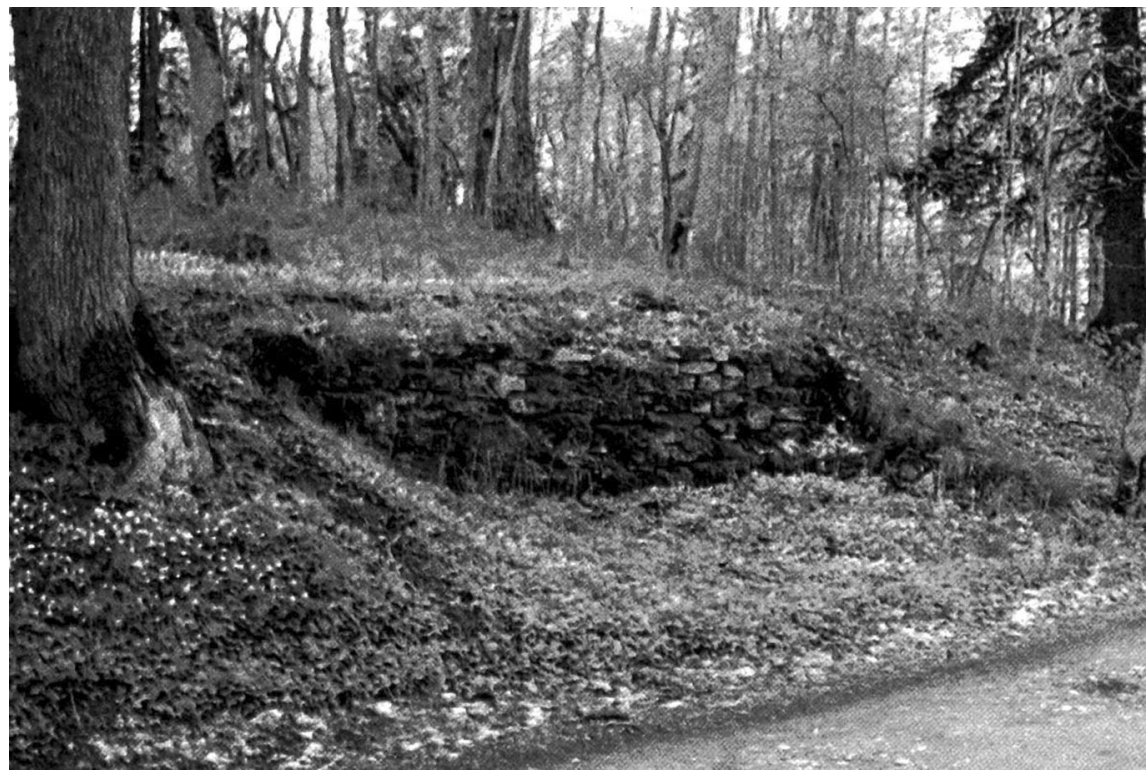

Abb. 28. Foto der freigelegten Mauerpartie auf dem Kraterrand (von Nordosten; Lõugas 1996, Taf. V). 
beschreibt die 470-metre-long stone wall als eine den Krater ursprünglich einschließende Umgrenzung, teilweise mit Resten der ursprünglichen Mauerbasis, bestehend aus großen, doppelt gereihten Granitfindlingen. Der massive Steinzirkel erreicht eine Dicke von 2,3-2,8 m. Nicht klar ist, ob dieser bereits zu Beginn als eine echte Begrenzungs- oder Schutzmauer konzipiert war oder als eine Art Steinkreis von symbolischer Bedeutung. Die Anlage ist in Teilen nachweislich neuzeitlich und wurde von Feldsteinen des benachbarten Gutshofs überbaut bzw. ergänzt. Laut Lõugas sollen an manchen Stellen der ursprünglich mehrschichtige Aufbau bzw. Ansätze einer Mauerung zu sehen sein (ebd., 358). An der von ihm archäologisch untersuchten Mauerpartie an der Südwestseite des Kraters, in einem Streifen von $10 \times 3 \mathrm{~m}$, kamen jedoch weder signifikante architektonische Details noch datierbare Funde zutage. Erwähnt werden - bis auf zahlreiche Tierknochen nur die Reste eines einzigen Tongefäßes, dass in seiner Machart als neuzeitlich eingestuft wird (ebd.). Abbildungen oder Beschreibungen zur Befundsituation (oder zum Gefäßfund) fehlen auch hier. Fragen nach der Datierung der ominösen Steinmauer bleiben vorläufig unbeantwortet. Das betrifft auch deren Funktion im Zusammenhang mit der Sakral- oder Opferplatztheorie. Interessant scheint diesbezüglich, dass im Innern der Mauer reichlich Tierknochen und -zähne auftraten, im Außenbereich jedoch keine. Aus dem Übergewicht an Zahnfunden gegenüber anderen tierischen Skelettbestandteilen und einer räumlich verdichteten Verteilung vorläufig bestimmter Tierknochen - Rind, Pferd, Schwein, Schaf/Ziege und Hund (keine Wildtiere) - schlussfolgerte Lõugas, dass es sich nicht um einen gewöhnlichen Platz mit Schlacht- oder Speiseabfall handeln könne. Vielmehr spräche alles für eine Art Opferstätte, allerdings spätmittelalterlichen oder neuzeitlichen Alters: Evidently those animals were sacrificed at that spot. It may have been done at the time when the church surveillance prohibited sacrifice in the lake. The foot of the former circular wall limited the place of sacrifice - the sacrificial animal had to be put behind it (ebd., 358). Eine vollständige osteologische Auswertung der Tierknochenabfälle ist bislang ausgeblieben, auf einen offiziellen Grabungsbericht lässt sich nicht zurückgreifen. Die Angaben bezüglich der Fundzusammensetzung und Fundzusammenhänge lassen sich nicht prüfen. Zumindest geht aus dem Zitat des Ausgräbers hervor, dass ein vorgeschichtlicher Zeitpunkt der Entstehung des äußeren Steinrings fraglich scheint. ${ }^{40}$ Das ist insofern bemerkenswert, weil einige Forscher von der Errichtung der äußeren Kratermauer in der Spätbronzezeit oder Vorrömischen Eisenzeit ausgehen. ${ }^{41}$

${ }^{40}$ Obwohl oder gerade weil Lõugas nur sehr vage Informationen zur vermeintlichen Befestigung der Kratersiedlung preisgab, haben seine knappen Ausführungen in der jüngeren Forschung eine Verkettung von Missverständnissen ausgelöst: One single sherd of a handmoulded pot from the uppermost wall-layer confirms that the construction took place in prehistoric times, perhaps contemporary with the fortification on the crater rim (Veski et al. 2004, 201; auch Kraut 2004, 57).

41 Es wurde aber die Idee formuliert, die Architektur der zweifachen Wall- oder Steinringanlagen von Siedlungen im Nordwesten Saaremaas (mit Datierung in die Vorrömische Eisenzeit) könne dem sog. Kaali-Komplex nachempfunden sein und somit (ebenfalls) im Sinne von Kultplatzaktivität interpretiert werden (Veski et al. 2004, 204, Abb. 5; 2007, 272, Abb. 15.6). Die entsprechenden Ringwallanlagen der Plätze Võhma und Pidula sind archäologisch nur ansatzweise über Probesondierungen erforscht. 
Verhaltene Kritik am in der jüngeren Kaali-Forschung gepflegten Umgang sowohl mit der Datierungsproblematik als auch mit Opfer- oder Kultplatztheorien wurde bereits an verschiedenen Stellen geäußert (Raukas et al. 2003; Jonuks 2009, 190 ff.). Auch ist festzustellen, dass im Zusammenhang mit Kaali die Anwendung bedeutungsschwerer Termini wie Kultstätte, Ritualort oder Opferplatz meist unreflektiert und ohne Auseinandersetzung mit der archäologischen Befundsituation erfolgte. Dies beruht im Wesentlichen auf folgenden Hypothesen: Die im Kraterrandbereich freigelegten Siedlungsspuren, mit Kalksteinplatten ausgelegte Wohnbauten oder Terrassen, haben Parallelen in den Bronzezeitplätzen Asva (Phase II) und Ridala. Auch die Feinkeramik und Gussformen stellen exklusive, nur die Siedlungen der Asva-Gruppe auszeichnende Fundgruppen dar. Die Trockenmauer überlagert die Spätbronzezeitphase, liefert aber sonst keine näheren datierenden Anhaltspunkte. Deren Bedeutung und Funktion ist fraglich, wird aber im Kontext von vorwiegend symbolisch-ideeller Abschirmung und Abgrenzung des durch Mauer und Ringwall markierten ,Sakralbereichs' aufgefasst. Die Deponierungen der Silberobjekte, angeblich im Innern des Mauerbereichs gefunden, gelten als Hauptargumente in diesem Interpretationsrahmen. Die den Kratersee und Ringwall umfassende Außenmauer, zwar ebenso unklar in Datierung und Funktion wie der innere Mauerring, wird eingepasst in die Gesamtkonzeption eines in verschiedenen Perioden frequentierten Kult- oder Sakralorts. Bislang erwies sich jedoch der Kratersee für das Team der von Lõugas geführten Archäologen und Geologen als ,undurchdringbar' bezüglich seiner in der Tiefe verborgenen Geheimnisse und lediglich die ältereisenzeitlichen Silberfunde sind, trotz ihrer schleierhaften Auffindungsumstände, als die einzigen Indizien für den Sakralortcharakter von Kaali anzusehen.

\subsubsection{Kaali - ein bronzezeitlicher Kultplatz?}

Es spricht einiges für sich, dass Kaali wegen seiner besonderen Topologie mit dem hoch aufgeschossenen Kraterrand und der kreisförmigen Senke mit einem Kratersee als ein in der vorgeschichtlichen Kulturlandschaft ungewöhnlicher Platz wahrgenommen wurde und die Menschen angeregt hat zu lokalen Mythenbildungen um dessen ,himmlische“ Entstehungsgeschichte (so bei Haas et al. 2003). Die zur allgemeinen Begeisterung für Opfer- oder Sakralplatztheorien angeregte symbolische Aura des Platzes geht wesentlich auf die religionsphänomenologisch inspirierte Vorstellung eines von der Außenwelt abgesonderten und geschlossenen „heiligen“ Raums zurück, der zu Zwecken von Ritual- oder Kulthandlungen frequentiert wurde (dazu z. B. Karl-Brandt 2011). Im Falle Kaali ist die Erwartungshaltung in der Forschung immer sehr hoch gewesen, solche an Ort und Stelle praktizierten Kulthandlungen im archäologischen Befund bestätigt zu sehen.

Hinweise auf bronzezeitliches Kultgeschehen gilt es aber noch zu erschließen. $\mathrm{Zu}$ erkennen geben können sich kultische Praktiken, auch solche der Weihung oder Opferung, über Niederlegungen bzw. Deponierungen von wertbehafteten oder 
bedeutungsgeladenen Objekten. Jedoch müssen sich aus der Kombination, Komposition und Behandlung dieser Objekte gewisse Muster und Regeln deuten lassen, um symbolische Intentionen im Umgang mit den Objekten vor und während der Niederlegung überhaupt zu erschließen. Schwierig ist es für die Archäologie, die jeweils möglichen Motivationen hinter rituellen Niederlegungen zu deuten, denn „Weihefunde“ oder „Opfer“ geben sich aus der Überlieferungssituation der Funde i. d. R. nicht als solche preis. Auch stellt sich die Frage, ob oder inwieweit solche kategorischen Trennungen zulässig sind bzw. ob diese von den an Niederlegungshandlungen Beteiligten als solche reflektiert oder intendiert wurden (so Oras 2014, 142). Zudem muss die Interpretation und Kategorisierung von Ritualhandlungen den jeweiligen Zeit- und Kulturkontext mitberücksichtigen, da dieser einflussnehmend ist auf die Art der Niederlegung und die Bedeutung und Bewertung von Objekten und Symbolik (Karl-Brandt 2011, 70 ff.; Oras 2014, 139 ff.). Die Bezeichnung „Opferplatz“, wie sie für Kaali generalisierend Anwendung findet, impliziert ganz konkrete Handlungen und Intentionen, die der derzeitige Fakten- und Untersuchungsstand nicht ansatzweise rechtfertigen kann. Die Frage stelle sich dennoch, ob für Kaali die Diskussion als ein potentieller Sakralort zulässig ist und was sog. Kultplätze kennzeichnet.

Wie bereits angemerkt, präsentiert sich ein Fundplatz wie Kaali, mit Kraterring und -see, in einem idealtopographischen Kontext mit einer markanten Visualität in der Kulturlandschaft und erscheint in seiner ausgeprägten symbolischen Aura geradezu prädestiniert als Anziehungspunkt für kultisch motivierte Handlungen und Niederlegungen. Versuche sind gemacht worden, aus dem Bau und der Anordnung von Ringwällen oder Mauern exponierter Plätze eine gewisse Symbolik der Abgrenzung zwischen sakralen und profanen Sphären abzuleiten, und aus diesen Vermutungen heraus diesen Orten einen Kultplatzcharakter zuzuschreiben (z. B. Veski et al. 2004; 2007). Auch Haus- und Grabarchitektur wird mit praktizierten Kulthandlungen in Verbindung gebracht, wenn es der archäologische Gesamtkontext wahrscheinlich macht. Ein bekanntes und in diesem Zusammenhang vielzitiertes Beispiel ist Tõnija Tuulingumägi auf Saaremaa, der als Versammlungsort, Kultstätte und Bestattungsplatz der Vorrömischen und Römischen Eisenzeit interpretiert wird (dazu Mägi 2001; 2005). ${ }^{42}$

In die künftige Diskussion um den Kraterplatz als mutmaßliche Stätte bronzezeitlichen Kultgeschehens sollten jedoch sämtliche archäologischen Hinterlassenschaften einbezogen werden, die von menschlichen Aktivitäten, sowohl sakrale als auch solche des profanen Bereichs, einbeziehen. In der Tat gibt es in Kaali genügend Hinweise für eine periodische Nutzung des Kraters als Wohn- und Siedlungsplatz, in der Spätbronzezeit und später. Im Fundmaterial sind Reibsteine und Mahlsteinunterlieger vertreten und gewisse Mengen tierischen Speise- und Schlachtabfalls sind

\footnotetext{
42 Mägi $(2013,7)$ weist in ihrem Bericht auf mögliche Beziehungen hin in Bedeutung und Funktion zwischen den rechteckigen Steinkonstruktionen von Kaali (siehe oben, Abb. 27) und Tõnija, nämlich im Sinne erhöhter Unterbauten (estn. platvorm) zur Praktizierung verschiedener Kulthandlungen. Sie ist sich aber des Dilemmas in der Datierung der Siedlungsbefunde von Kaali bewusst.
} 
gleichfalls Beleg der Nahrungsverarbeitung und Tierhaltung vor Ort (Kap. 10 f.). Von der symbolischen Aura im Zusammenhang mit dem Sakralortcharakter abgesehen, boten Kratersee und Wall vermutlich günstige Bedingungen für Wasserversorgung und Haustierhaltung. Sicherheits- und verteidigungsstrategische Aspekte mögen bei der Platzwahl ebenso eine Rolle gespielt haben. Das Typenspektrum des keramischen Fundmaterials bietet, soweit bei der vergleichsweise kleinen Menge an bestimmbaren Materials festzustellen möglich, Raum für Interpretationen bezüglich sowohl profaner als auch sakraler Nutzung der Keramik. Der Formen- und Typenschatz der Kaali-Keramik entspricht dem der Gefäßkeramik von Asva, Ridala und Iru, und bezeugt eine breite Palette an Funktionsbereichen der Grob- und Feinkeramik (Kap. 8). Angesichts der Exklusivität in der Verbreitung der Henkelschalen im Ostseeraum der Bronzezeit bietet sich aber die Möglichkeit, die Feinkeramik der Kratersiedlung als Hinterlassenschaften besonderer Handlungen im Rahmen gesellschaftlicher oder kultischer Anlässe zu sehen (z. B. Trinkfeste; dazu Eriksson 2008; 2009; Kap. 8). Ebenso liefern die Gießerfunde (Ringgussformen) Diskussionspotential in der Deutung des Kraters als Kultplatz, denn im Kontext der Nordischen Bronzezeit gibt es Beispiele für Bronzeguss an Sakral- oder Bestattungsplätzen, die Spuren der Metallverarbeitung können also auch auf kultisch-sakral motivierte Handlungen weisen (siehe Goldhahn \& Oestigaard 2008). Auch die aus der Insel Saaremaa stammenden Metallobjekte der Bronzezeit lassen eine Verbindung zu kultischen und religiösen Vorstellungen und Praktiken erkennen - sich äußernd in der Hortung oder Niederlegung von Metallwerten. Funde wie der Bronzebruchhort von Tehumardi (oder aus dem lettischen Staldzene), sind in der wiederkehrenden Komposition und Behandlung der niedergelegten Objekte als Zeugnisse überregional verbreiteter Ritualhandlungen anzusehen. Sie sind seltene, aber anschauliche Beispiele der Übernahme nordischer Kult- und Glaubensvorstellungen (dazu Sperling 2013). Kaali ist auch in diesem Kontext zu nennen, denn der Kraterplatz wird als Fundort einer nordischen Scheibenkopfnadel vom Typ Härnevi genannt (Fundumstände unklar; Lõugas \& Selirand 1989, 209 f.). Solche Nadeln mit überdimensionierten Kopf und konzentrischem Rillenmuster (Sonnensymbolik?) treten im Ostseeraum der Spätbronzezeit vorzugsweise einzeln auf (Einstückdeponierung), ansonsten in gemischten Niederlungen (Mehrstückhorte). Eine andere typengleiche Scheibenkopfnadel) kam in Asva während der Siedlungsgrabung zutage (siehe Kap. 7.4.7.1). Es ist also denkbar, dass die Scheibenkopfnadeln an ausgesuchten Plätzen, auch einzeln, deponiert wurden. Auf Kaali werfen die sog. Härnevi-Nadeln ein interessantes Licht, weil der namengebende Hortfund aus dem schwedischen Uppland als ein herausragendes Beispiel für bronzezeitliches Kultgeschehen interpretiert wird (Forsgren 2010; 2012). Plätze von mutmaßlichem Sakralortcharakter stellen eine von der Bronzezeitforschung bislang marginal behandelte Quellengruppe dar, aber es mehren sich die Erkenntnisse, dass es in der Bronzezeit in Bezug auf Ort und Art der Niederlegung von Objekten mit Wert und Symbolik feste Regeln und Vorstellungen gegeben haben muss. Ganz offensichtlich wurden für Metalldeponierungen Orte und Plätze aufgesucht, die metaphorischen Grenzbereichen entsprachen 
(Karl-Brandt 2011; Hansen 2013; Neumann 2013). So wurden in der Nordischen Bronzezeit Moore oder Gewässer für Metallniederlegungen bevorzugt und auch der Kratersee von Kaali erhält vor diesem Hintergrund eine gewisse Symbolik als Tor zur transzendenten Welt. In diesem Zusammenhang sind auch die aktuellen Forschungen Martin Rundkvists zu rituellen Hortfundlandschaften in der Mälarsee-Region (auch Uppland) von Interesse, denn sein Fokus richtet sich auf die Rekonstruktion räumlich-topographischer Bezüge potentieller Sakral- und Deponierungsorte (sacrificial sites). Seiner Auffassung nach kennzeichnet Plätze wie Härnevi the attractiveness of wet, high, topographically dramatic and ancestral locations to Bronze Age sacrifices (Rundkvist, im Druck). In der Ansprache als hypothetischen Handlungsort bronzezeitlichen Kultgeschehens vereinigt der Kraterplatz von Kaali all diese Attribute und rechtfertigt den hypothetischen Bezug zur Sakralorttheorie. Wie oben dargelegt, bedarf es in künftigen Untersuchungen zu dieser Thematik aber einer emotional gemäßigteren Erwartungshaltung, speziell in der Revision der archäologischen Überlieferungssituation in Kaali und mit Blick auf die für profan-alltägliche Siedlungsaktivitäten sprechenden Funde und Befunde.

\subsection{Iru}

Der Fundplatz Iru kann zu den prominentesten der Burgwälle, Wallanlagen und befestigten Höhensiedlungen Estlands gezählt werden. Der Burgberg ist über mehrere Perioden hinweg besiedelt worden, wesentliche Teile der Fortifikation stammen aus der Mittleren und Jüngeren Estnischen Eisenzeit (2. Hälfte des 1. Jahrtausends u. Z.). Die über $5.000 \mathrm{~m}^{2}$ große Anlage ist seit den 1930er Jahren in Abständen archäologisch untersucht worden, mittlerweile wurde ca. ein Viertel davon ausgegraben (Abb. 29).

Sie liegt auf einem erhöhten Geländesporn ca. $10 \mathrm{~km}$ entfernt vom Zentrum der estnischen Hauptstadt. Die Küste ist ungefähr 4,5 km entfernt. Das Siedlungsplateau mit seinen steilen Abhängen hebt sich von der Umgebung 9-12 m empor. Der Sporn selbst wird von der West- und Ostseite vom Fluss Pirita umlaufen. In der Länge und Breite erstreckt sich die besiedelte Terrasse mit Wallanlagen auf 212,5 bzw. 16-52 m (Lang 1995b, 53 f., Abb. 1). Die Grabungen der Jahre 1936-1938, 1952-1958 und 1984-1986 (Indreko, Vassar und Lang) erbrachten detaillierte Einblicke in die Siedlungsabfolge an diesem Platz. Verschiedene Phasen sind entweder über Keramik und sonstige Funde oder über konkrete Befunde (Hausstrukturen, Mauer- und Wallkonstruktionen) nachweisbar. Die ältesten drei gehören dem Spätneolithikum (Spätphase der Bootaxtkultur), der Spätbronzezeit sowie der Vorrömischen Eisenzeit an. Der Mittleren und Späten Estnischen Eisenzeit können fünf Wohn- und Bauphasen zugeschrieben werden, im Zuge derer die Errichtung umfangreicher Befestigungsmauern und -wälle im Süden und Norden sowie auf dem zentralen Plateau, inklusive Resten einer turmartigen Struktur, stattfand. V. Lang (1987a; 1996; 2007a; 2007b) hat die Grabungsergebnisse zu Aufbau und Besiedlung von Iru detailliert dargestellt und geschildert. 


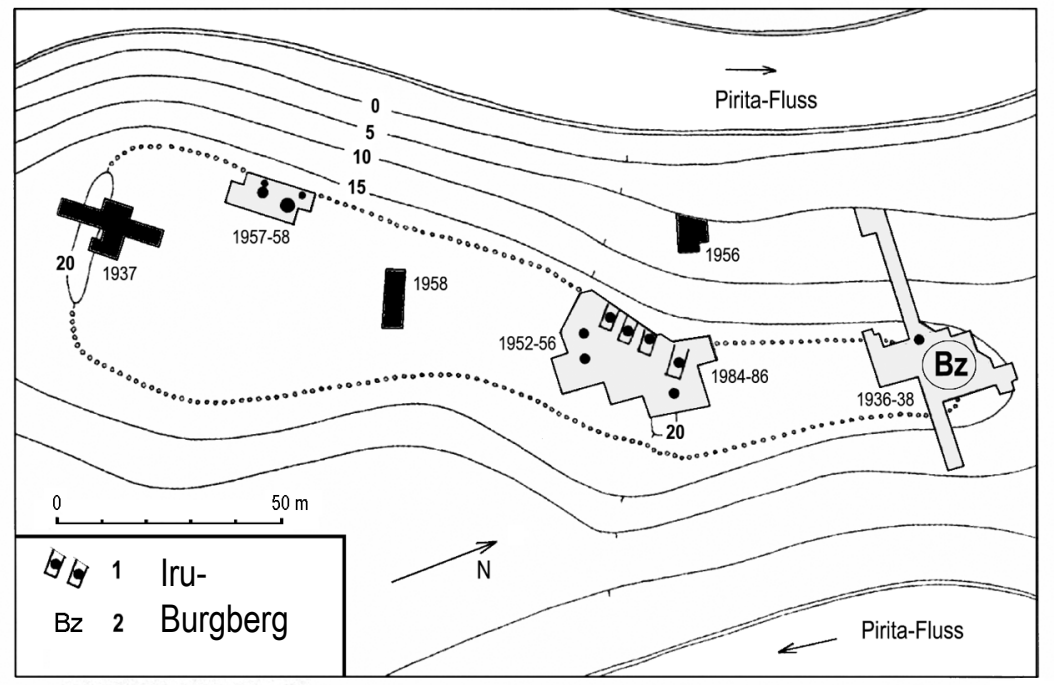

Abb. 29. Der Burgberg von Iru und die Grabungsteile mit Spuren der spätbronzezeitlichen Besiedlung (grau gefüllt). 1 Hausgrundrisse und Herdstellen, 2 Gießerplatz (nach Lang 2007b, Abb. 19).

Die spätbronzezeitliche Besiedlungsphase von Iru begegnet in der Literatur als Periode der fortified settlement, obwohl das Fehlen jeglicher Befestigungsspuren eingeräumt wird (Lang 1995b, 54; 2007b). Dabei wird vorausgesetzt, dass die Platzwahl auf dem erhöhten Terrain an sich bereits ein Schutzbedürfnis ausdrückt, außerdem wird so die synchrone Existenz mit den anderen Siedlungsplätzen der Asva-Gruppe von mutmaßlicher Verteidigungsdisposition betont.

Bronzezeitliche Befunde, begleitet von Keramik und auch einigen Metallobjekten (u. a. eine Lanzenspitze, zwei Ringfragmente, vier Bronze- und ein Eisenpfriem), kamen hauptsächlich in Grabungen der 1950er und 1980er auf dem Mittelteil des Nordplateaus zum Vorschein. Die Strukturen von mindestens vier Häusern wurden dort entlang der Westkante in West-Ost Ausrichtung freigelegt. Über die Bodenverfärbungen und Lage der Pfostenbauten (steingestützt) konnten Bauten in Blockbautechnik, ca. $10 \mathrm{~m}$ lang, 3-5 m breit, rekonstruiert werden (Lang 2007b, 58 f., Abb. 20). Das Fundmaterial ähnelt in vielen Aspekten und Details dem von Asva und Ridala. Die Knochen-, Geweih- und Steingeräte belegen eine ganz ähnlich vielseitige Subsistenz in Iru wie bei den Siedlungen auf der estnischen Ostseeinsel. Dem Geräterepertoire zufolge wurden neben der Viehzucht und dem Feldbau (u. a. Ardspitzen, Mahlsteine) auch Robbenfang (Harpunen) betrieben und die dabei anfallenden Agrar- und Fangprodukte vor Ort verarbeitet. Die Keramik von Iru zeigt ebenfalls ganz ähnliche Züge gegenüber der AsvaKeramik. Die Fundausbeute an ca. 4.150 Gefäßscherben aus Iru ist verglichen mit Asva (ca. 26.200 Stück) eher klein und Ausdruck einer weniger intensiven oder andauernden Bronzezeitbesiedlung an diesem Ort. Auch scheint es sich bei Iru nur um eine einmalige Siedlungsperiode zu handeln. 
Bronzezeitliche Siedlungsfunde kamen auch im Nordteil der Siedlung zutage (Grabungen 1936-1938). Neben Herdstellen und Keramikfunden konnte dort der für die Asva-Gruppe charakteristische Bronzeringguss nachgewiesen werden. Bis auf einzelne Ausnahmen fanden sich die keramischen Ringgussformen (über 60 Fragmente) nur im Nordteil von Iru (Lang 2007b, 59, 116, Abb. 19, 53). Der Umstand, dass Spuren der Metallproduktion in Estland und Nachbarregionen nur in Siedlungen an ausgewählt verkehrsstrategischen Standorten und mit komplexer Subsistenz vorkommen, macht auf die bedeutende Rolle des Metalls in der Siedlungsökonomie aufmerksam. Die folgenden, von Asva ausgehenden Untersuchungen werden auch für Iru klären helfen, ob die Lokalisierung des Metallhandwerks als eine an und für sich elitäre Tätigkeit zwangsläufig auf privilegierte Bevölkerungsteile mit gesellschaftlicher und ökonomischer Vormachtstellung hinweisen muss (Metallmonopol?). Immerhin wird der Höhensiedlung eine soziopolitische Mittelpunktstellung in der für seine verdichtete archäologische Fundpräsenz bekannten Pirita-Region zugeschrieben (u. a. Lang 2003, 185 ff.; 2007b, 94, 264 f.). 